TITLE:

\title{
Formation mechanism of metal nanoparticles studied by XAFS spectroscopy and effective synthesis of small metal nanoparticles
}

\section{$\operatorname{AUTHOR}(S)$ :}

Tanaka, Tsunehiro; Ohyama, Junya; Teramura, Kentaro; Hitomi, Yutaka

\section{CITATION:}

Tanaka, Tsunehiro ... [et al]. Formation mechanism of metal nanoparticles studied by XAFS spectroscopy and effective synthesis of small metal nanoparticles. Catalysis Today 2012, 183(1): 108-118

\section{ISSUE DATE:}

2012-03

URL:

http://hdl.handle.net/2433/154890

\section{RIGHT:}

C 2011 Elsevier B.V.; この論文は出版社版でありません。引用の際には 出版社版をご確認ご利用ください。; This is not the published version. Please cite only the published version. 
TITLE.

Formation Mechanism of Metal Nanoparticles Studied by XAFS Spectroscopy and Effective Synthesis of Small Metal Nanoparticles

\section{AUTHOR NAME.}

Tsunehiro Tanaka, ${ }^{a,}$, Junya Ohyama ${ }^{b}$, Kentaro Teramura ${ }^{a}$, and Yutaka Hitomi ${ }^{c}$

\section{AUTHOR ADDRESS.}

a. Department of Molecular Engineering, Graduate School of Engineering, Kyoto University, Kyoto 615-8510, Japan

b. Department of Molecular Design and Engineering, Graduate School of Engineering, Nagoya University, Nagoya 464-8603, Japan

c. Department of Molecular Chemistry and Biochemistry, Faculty of Science and Engineering, Doshisha University, Kyotanabe 610-0321, Japan.

\section{CORRESPONDING AUTHOR.}

Professor Tsunehiro Tanaka

Department of Molecular Engineering, Graduate School of Engineering, Kyoto University, Kyoto 615-8510, Japan

Tel: +81-75-383-2558 Fax: +81-75-383-2561

E-mail address: tanakat@moleng.kyoto-u.ac.jp

Keywords; metal nanoparticle, formation mechanism, DXAFS, QXAFS, Photodeposition 


\begin{abstract}
.
Recently, we studied and developed two useful synthesis methods of metal nanoparticles. The first system is wet chemical synthesis of gold nanoparticles using fast reduction. The second one is photodeposition of metal nanoparticles on $\mathrm{TiO}_{2}$. The X-ray absorption fine structure (XAFS) study revealed their unique formation mechanisms different from the conventional mechanisms. Furthermore, we designed and synthesized new multidentate protecting ligand having sulfur functional groups to synthesize small gold nanoparticles efficiently.
\end{abstract}

\title{
MANUSCRIPT TEXT.
}

\section{Introduction}

\section{1. Wet chemical synthesis of metal nanoapariticles}

There has been considerable interest in the unique properties of metal nanoparticles, such as catalytic activity, optical, and magnetic properties. ${ }^{1-4}$ Their unique properties depend on their size, therefore, the size control synthesis of metal nanoparticles is demanded. Among the synthesis methods, wet chemical synthesis is one of the most useful methods for metal nanoparticles having well-defined size.

Metal nanoparticles can be easily synthesized by reduction of metal salts in solution (wet chemical synthesis). As reducing agents, for example, citric acid, ascorbic acid, borohydride, diborane, hydrogen, and alcohol are utilized. When citric acid or ascorbic acid are used, the resulting metal nanoparticles are stabilized by electrostatic repulsion due to the adsorbed citric or ascorbic acid ions on the surface of metal. ${ }^{5}$ On the other hand, when the reducing agents which do not prevent aggregation of particles are used, 
protecting ligands are applied to hinder particle aggregation sterically. Polymers such as polyvinylpyrroldone, polyvinylalcohol, and polyvinylether are often utilized as protecting ligands, particularly in alcohol reduction process which is one of the most widely used methods in the wet chemical synthesis. ${ }^{6-9}$ In this process, metal ions are reduced by heated alcohols in the presence of protecting ligands. Polyols (e.g. ethylene glycol) are also applied in the same manner as alcohol. ${ }^{10}$ When surfactants (e.g. alkyl ammonium compounds) are utilized as protecting ligands, they form micelle or inverse micelle in a solution, which provide not only reaction field for formation of metal nanoparticles but also protecting layer for metal nanoparticles. ${ }^{11}$ Schiffrin and Brust developed the inverse micelle method by using an alkanethiol as a protecting ligand which strongly binds to a surface of metal nanoparticles and self-assembles into monolayer on metal surface to prevent the coalescence of metal nanoparticles (Schiffrin-Brust method). ${ }^{12}$ It is also worth noting that they used sodium borohydride as a reducing agent. As a result, monodisperse small gold nanoparticles covered with thiolates were synthesized. There are other wet chemical synthesis methods, for example, heat and photolytic degradation of organic metallic compounds, ${ }^{13,14}$ reduction of ligands of metallo-organic complexes, ${ }^{15}$ and so on. In addition, various protecting agents are applied to each synthesis method of metal nanoparticles. Owing to these efforts, very recently, a number of atomically monodisperse nanoparticles have been available. ${ }^{16,17}$ For synthesis of a series of precisely size-controlled metal particles, the studies on preparation methods are now underway.

\section{2. Formation mechanism and size control synthesis of metal nanoaparticles}

The formation mechanism of metal nanoparticles has been studied to elucidate the 
effect of the preparation conditions on the size of metal nanoparticles. In 1950, LaMer et al. studied the formation mechanism of sulfur sol, and proposed that the sol is formed by fast nucleation from supersaturated solution of monomer and growth by attachment of monomers to the resulting nuclei. ${ }^{18}$ The LaMer mechanism has been applied to formation mechanism of the metal nanoparticles by wet chemical synthesis. ${ }^{19}$ On the other hand, Finke et al. have studied the formation kinetics and mechanism of Ir nanoparticles from the precursors by $\mathrm{H}_{2}$ reduction. ${ }^{19}$ They proposed a different mechanism from LaMer one; nuclei are formed slowly but constantly and the nanoparticles grow mainly by autocatalytic reduction of metal precursors on the particle surface. Although both of the mechanisms are different in kinetics of nucleation and growth, particles mainly grow by the addition of monomer (precursor) on the particle surface in the both mechanisms. In contrast, Baiker et al. proposed that combination/coalescence of particles is the dominant growth mechanism for the gold particles prepared by using strongly reducing and protecting agent. ${ }^{20}$ Furthermore, other mechanisms such as thermodynamic factors and Ostwald ripening have been also proposed. ${ }^{21-23}$ Thus, particle formation mechanism is still unclear. This is due to the difficulties of observation of the formation process, more specifically the nucleation process. Since the formation mechanisms can be utilized as a guide line for design of morphology of metal nanoparticles, it is necessary to investigate particle formation mechanism more closely.

Here, we would like to consider how the size of metal nanparticles can be controlled on the basis of a simple particle formation mechanism shown in Scheme $1 .^{24}$ When particles grow by addition of metal atoms on a surface of particle without Ostwald ripening and aggregation between particles, the size should vary with the number of 
nuclei, in other words, relative rate of nucleation to growth. The high relative rate increases the number of particles and leads the small particles. On the contrary, the low relative rate results in the low concentration of particles and thus formation of large metal particles. Therefore, understanding and manipulation of the relative rate of nucleation to growth is critical for the size control of metal nanoparticles. The relative rate can be controlled by reduction rate of metal precursors, the initial molar ratio of a passivant to a metal precursor, and the affinity of passivants for metal species and the structure of passivants.

The reduction rate of metal precursors has an effect on the particle size. Teranishi et al. reported the dependence of the size of gold nanoparticles protected by PVP on the kinds of reducing agents, alcohols and potassium borohydride. ${ }^{25}$ The reduction with alcohols provided polydispersed gold nanoparticles having 2-14 $\mathrm{nm}$ diameter. But, potassium borohydride, which reduce gold ions faster than alcohols, afforded monodispersed particles with ca. $2 \mathrm{~nm}$ diameter. They also investigated the variation of the particle size with the amount of potassium borohydride, and showed that the particle size increases as a decrease in the concentration of potassium borohydrides. This result indicates that the fast reduction of gold ions causes the formation of large number of nuclei and provides small particles. In the case of the preparation of platinum and palladium nanoparticles using alcohol reduction method, the easily oxidized alcohol gave the small metal nanoparticles. ${ }^{26,27}$ Therefore, the rapid reduction of metal ions would cause fast nucleation, resulting in formation of many nuclei and thus small metal nanoparticles.

Small metal nanoparticles are generally formed at high molar ratio of protecting agents to precursors. The large amount of protecting agents will suppress the growth of metal 
nanoparticles, which makes the relative rate of nucleation to growth fast and provides small metal nanoparticles. ${ }^{21,26-29}$ However, there is an exception; Weller et al. reported that the size of $\mathrm{CoPt}_{3}$ increased with an increase in the ratio of 1-adamantanecarboxylic acid to metal precursors. ${ }^{24}$ They proposed that the protecting agents strongly stabilize the metal precursors, and the large amount of the protecting agents decreases the nucleation rate. As for the preparation of gold nanoparticles covered with alkanethiol, the particle size decreases from 5 to $2 \mathrm{~nm}$ with an increase in the ratio of alkanethiol to gold ion. ${ }^{21}$ This variation of particle size can be explained by the kinetic control mechanism. But, Leff et al. proposed that the size of gold nanoparticles with alkanethiol is determined by the thermodynamic factors for surface stabilization rather than the relative rate of nucleation to particle growth. ${ }^{21}$ Although size control by a ratio of protecting agents to metal precursors is easy and useful, it is necessary to understand the role of protecting agents in a particle formation process in more detail.

As described above, the affinity of protecting agents for metal precursors influence the size control behavior. The interaction of protecting agents to the surface of metal can also affect the size of metal nanoparticles. For example, the protecting ligands with thiol and cyano groups, which are known to have a high affinity for gold, give smaller and narrower size-distributed gold nanoparticles than the protecting ligands with carbonyl and alcohol groups having a low affinity for gold. ${ }^{25}$ On the other hand, the use of multidentate ligands has been employed by several groups in effort to stabilize metal nanoparticles. For example, multidentate ligands inhibit the aggregation of metal nanoparticles in organic solvents. ${ }^{30,31}$ Multidentate ligands also increase the monodispersity of the resultant metal nanoparticles with an increase in the number of coordinate position of ligands. ${ }^{31}$ Recently, such ligands have been attracted the attention 
for the synthesis of size-specific metal nanoparticles, because the structure of ligands and their unique stabilization of particle surface can contribute the structure of metal particles. ${ }^{32}$ However, it is still unclear how the ligand structure acts in formation of metal nanoparticles.

\section{Synthesis of small gold nanoparticles}

Gold nanoparticles show unique properties deviated from the bulk, for example, catalytic reactivity and optical properties. ${ }^{1,3}$ Of particular interest is the dramatic change of the properties of gold nanoparticles with less than ca. $2 \mathrm{~nm}$ diameter. ${ }^{1}$ In order to efficiently synthesize such small gold nanoparticles, we designed and synthesized new protecting ligand $\mathbf{1}$ shown in Scheme 2, which displays four sulfur atoms via rigid linkers in the same direction perpendicular to the porphyrin plane. ${ }^{33}$ The ligand $\mathbf{1}$ is expected to build up fast and tight connections with gold surface via four Au-S bonds since all the four $\mathrm{S}$ atoms are pre-oriented to form $\mathrm{Au}-\mathrm{S}$ bonds and do not rotate away due to steric hindrance between the amide moiety and the porphyrin plane, as demonstrated with the Collman's picket fence porphyrin. ${ }^{34}$ We synthesized gold nanoparticles protected by $\mathbf{1}$ (GN@1) on simple one-phase method, that is, $\mathrm{NaBH}_{4}$ reduction of $\mathrm{HAuCl}_{4}$ in a DMF solution containing $\mathbf{1}$, in order to evaluate the intrinsic ability of the passivant to produce and stabilize gold nanoparticles without any assistance by other co-stabilizers such as citrate or TOAB. ${ }^{35,36}$

Figure 1 shows a representative TEM image of GN@1, where crystal lattice of gold was observed. Particle analysis revealed that GN@1 has a mean diameter of $3.5 \pm 0.7$ $\mathrm{nm}$. The size of alkanethiol-protected gold nanoparticles has been demonstrated to be controlled by the initial thiol/gold ratio $(\xi) .{ }^{37}$ Therefore, we prepared GN@1 at various 
ratios of 1 to $\mathrm{HAuCl}_{4}$ from 0.025 to 4 , which correspond to $\xi$ values from 0.1 to 16 . Analyzed particles sizes are plotted against $\xi$ values in Figure 2, where the particle size decreased down to ca. $2 \mathrm{~nm}$ as increasing $\xi$ to 16 . To evaluate the capability of $\mathbf{1}$ to control the size of formed gold nanoparticles, as a control we synthesized a monodentate surface passivant ligand (2) whose structure was taken from 1 (Scheme 2), and prepared monodentate-thiol-protected gold nanoparticles (GN@2) at different values of $\xi$ from 0.1 to 16 . The particle size of $\mathbf{G N @ 2 ~ d e c r e a s e d ~ a s ~ o b s e r v e d ~ f o r ~}$ GN@1, but was larger than those of GN@1 when compared at the same value of $\xi$ (Figures 1 and 2). We also prepared dodecanethiol-protected gold nanoparticles GN@DT by the one-phase method, since dodecanethiol is known to stabilize gold nanoparticles by forming a closely packed self-assembled monolayer and would give smaller gold nanoparticles. In fact, however, the size of GN@DT was larger than that of GN@1 at every value of $\xi$, i.e. larger by $1.0 \mathrm{~nm}$ at $\xi=16$. Thus, the passivant ligand $\mathbf{1}$ tends to produce smaller gold nanoparticles than monodentate passivant $\mathbf{2}$ and dodecanethiol.

GN@1 prepared at $\xi=1$ was characterized by UV-vis. spectroscopy after purification by repeated precipitation with methanol and chloroform to remove unbound ligand $\mathbf{1}$. The spectrum showed both features characteristic of porphyrin and gold nanoparticles; the Soret and Q bands at $426 \mathrm{~nm}$ and 500 to $670 \mathrm{~nm}$, respectively, and the surface plasmon band at around $530 \mathrm{~nm}$. The Soret band for GN@1 was significantly broadened and red-shifted compared with that for $\mathbf{1}$ before reduction; $426 \mathrm{~nm}$ (FHW 13 nm) for GN@1 vs. 422 nm (FHW 9.6 nm) for 1, suggesting the electronic interactions between gold nanoparticles and the porphyrin and/or side-by-side alignment of $\mathbf{1}$ on the gold surface. ${ }^{38,39}$ On the other hand, the chemical status of the four S atoms of GN@1 
was inspected by using X-ray photoelectron spectroscopy (XPS). The result indicated that 1 supports the surface of gold nanoparticles with four S atoms having no acetyl group. Thus, the porphyrin plane of $\mathbf{1}$ orients in a plane parallel to the gold surface. Such a horizontal monolayer formation of $\mathbf{1}$ on gold surface is in agreement with the red-shifted Soret band of GN@1. It is likely that the multidentate ligation of $\mathbf{1}$ to the gold surface and the relatively large porphyrin moiety may play a role in producing smaller gold nanoparticles. . $^{30,35,40}$

It is noteworthy that the ligand $\mathbf{1}$ has four thioester groups, but the XPS analysis indicated that the $\mathrm{S}$ atoms lack acetyl groups and exist as thiolate anions on a gold surface. Thioester groups do not adsorb onto a gold surface rapidly compared to the corresponding thiol functional groups. ${ }^{41,42}$ Therefore, we tried to deprotect the acetyl groups of $\mathbf{1}$ in an attempt to realize more efficient capping of small gold nanoparticles. Unfortunately however, we failed to isolate any monomeric porphyrin compounds, instead always obtaining insoluble polymers, probably due to the formation of intermolecular disulfide bonds. We then designed a new porphyrin-based ligand $\mathbf{3}$ that has a structure similar to $\mathbf{1}$ except for one more methylene in each arm (Scheme 3). Mild hydrolysis of $\mathbf{3}$ followed by aeration nearly quantitatively yielded monomeric porphyrin compound 4 , which has two disulfide bonds over one face of the porphyrin plane (Scheme 3). ${ }^{43}$

In order to evaluate the ability of $\mathbf{4}$ to control the size of gold nanoparticles, we estimated the particle size of GN@3 and GN@4 prepared at five different $\xi$ values by TEM measurements. Analyzed particle sizes (diameter in $\mathrm{nm}$ ) are plotted against $\xi$ in Figure 3. The particle size of $\mathbf{G N @ 3 ~ d e c r e a s e d ~ f r o m ~} 6.2 \pm 1.4 \mathrm{~nm}$ and reached approximately $2 \mathrm{~nm}$ as the $\xi$ value changed from 0.1 to 16 , which is very similar to that 
observed for GN@1 (vide supra). On the other hand, the particle size of GN@4 was 3.8 $\pm 0.4 \mathrm{~nm}$ even at $\xi=0.1$ and reached ca. $2 \mathrm{~nm}$ as the $\xi$ value increased. Thus, the ligand 4 gave much smaller gold nanoparticles than conventional protecting ligand. This clearly demonstrates that the disulfide ligand $\mathbf{4}$ efficiently capped the small growing gold nanoparticles due to the fast formation of $\mathrm{Au}-\mathrm{S}$ bonds without deprotection of acetyl groups. The protecting ligand having multivalent disulfide bonds should be promising candidates for constructing monolayer-protected gold nanoparticles of well-defined size.

\section{Formation mechanism of gold nanoparticles}

The formation process of metal nanoparticles is still unclear due to only a few effective techniques for in-situ observations. Of these techniques, time resolved X-ray absorption fine structure (XAFS) spectroscopy is one of the most useful methods to observe metal nanoparticle formation process in situ because the chemical state and the structure of metal nanoparticles can be analyzed from the spectra. ${ }^{44-51}$ Recently, a coupled in situ XANES and small-angle X-ray scattering (SAXS) spectroscopy was applied to elucidate the formation mechanism of gold nanoparticles from a solution of $\mathrm{Au}^{3+}$ ions with citrate acid. ${ }^{52}$ These studies helped describe the mechanism of nanoparticle formation, which was found to comprise different steps of particle growth via both the coalescence of nuclei and further monomer attachment. However, the spectral analyses did not clearly reveal the formation of nuclei. On the other hand, we succeeded in observing the formation of nuclei in the solution using the in-situ quick XAFS spectroscopy (QXAFS) on the BL40XU beamline in SPring-8 of the Japan Synchrotron Radiation Research Institute (JASRI; $8 \mathrm{GeV}, 100 \mathrm{~mA}$ ) with millisecond time 
resolution. $^{53}$

\section{1. The formation mechanism of gold nanoparticles protected by dodecanethiol}

We observed the formation process of gold nanoparticles prepared by $\mathrm{NaBH}_{4}$ reduction of $\mathrm{Au}^{3+}$ in toluene, in the presence of dodecanethiol (DT) ${ }^{54}$ This is one of the most popular methods used to prepare gold nanoparticles, as represented by the Shiffrin-Brust method. ${ }^{12}$ The XAFS measurement was performed with a $100 \mathrm{~ms}$ time resolution. Figure 4 shows the series of Au $L_{3}$ edge XANES spectra during particle formation, together with those of $[\mathrm{TOA}] \mathrm{AuCl}_{4}$ in toluene $\left(\mathrm{Au}^{3+}\right.$ solution), $\mathrm{Au}$ foil, $\mathrm{Au}_{11}\left(\mathrm{PPh}_{3}\right)_{8} \mathrm{Cl}_{3},{ }^{55}$ [TOA] $\mathrm{AuCl}_{2}\left(\mathrm{Au}^{+}\right.$solution $)$as references. The XANES spectrum of $\mathrm{Au}^{3+}$ solution has sharp and narrow absorption band around the edge $(11920 \mathrm{eV})$, which is called the white line. The band corresponds to the electronic transition from the $2 p_{3 / 2}$ core level state to the vacant $5 d_{3 / 2}$ and $5 d_{5 / 2}$ states. The XANES spectrum of the Au foil exhibits almost no white line because of the almost fully filled $5 \mathrm{~d}$ state of $\mathrm{Au}^{0}$. The solution of $\xi=1$ before addition of $\mathrm{NaBH}_{4}$ represented the smaller white line than $\mathrm{Au}^{3+}$ solution. This is due to the reduction of an $\mathrm{Au}^{3+}$ ion by 2 molecules of DT to form $\mathrm{Au}^{+}$ ion. In other words, the solution of $\xi=1$ before addition of $\mathrm{NaBH}_{4}$ contains an equal quantity of $\mathrm{Au}^{+}$and $\mathrm{Au}^{3+}$ ions, which was confirmed by the least squares fitting of the XANES spectrum before the reduction with the linear combination of the those of $\mathrm{Au}^{3+}$ and $\mathrm{Au}^{+}$solutions. The white line of the solution of $\xi=1$ disappeared immediately after addition of $\mathrm{NaBH}_{4}$, and, alternatively, the small and broad peak appeared just at the high-energy side of the edge $(11929 \mathrm{eV})$. The peak intensity became the strongest at 4.6 s. The XANES spectrum exhibits the most specific small peak at $4.6 \mathrm{~s}$. A similar small peak is also observed in the XANES spectrum of $\mathrm{Au}_{11}\left(\mathrm{PPh}_{3}\right)_{8} \mathrm{Cl}_{3}$, but it is not observed in that of $\mathrm{Au}^{+}$ions. This result suggests that very small gold nanoparticles, i.e., $\mathrm{Au}$ 
nuclei, are formed at $4.6 \mathrm{~s}$. The XANES spectra obtained before the formation of the Au nuclei were fitted by the spectra of the $\mathrm{Au}$ nuclei and the $\mathrm{Au}^{+}$solution, which indicates that $\mathrm{Au}^{+}$ions are the intermediate in the formation process of the $\mathrm{Au}$ nuclei. Furthermore, the appearance of the small peak around the edge immediately after the addition of $\mathrm{NaBH}_{4}$ indicates that DT passivates $\mathrm{Au}$ just after the reduction of $\mathrm{Au}$ ions to $\mathrm{Au}^{0}$, because the small peak is derived from the formation of $\mathrm{Au}-\mathrm{S}$ bonds and $\mathrm{Au}$ ions do not have Au-S bonds. After the formation of Au nuclei at $4.6 \mathrm{~s}$, the intensity of the small peak at $11929 \mathrm{eV}$ decreased with time, and the two broad bands at 11948 and $11970 \mathrm{eV}$ appeared. In short, the XANES spectra became similar to that of the Au foil. The spectral change indicates the reduction of $\mathrm{Au}$ ions and the formation of gold nanoparticles.

The extended XAFS (EXAFS) spectrum at $4.6 \mathrm{~s}$ (Figure 5) was analyzed to investigate the structure of $\mathrm{Au}$ nuclei. Unfortunately, the low amplitude and low $\mathrm{S} / \mathrm{N}$ ratio of the EXAFS spectrum did not allow determination of appropriate structural parameters by curve fitting of the Fourier transformed EXAFS spectrum. However, a similar EXAFS spectrum as that obtained at $4.6 \mathrm{~s}$ was represented by the linear combination of $12.5 \%$ of the EXAFS spectrum of the $\xi=1$ solution and $25 \%$ of that of Au foil. The coordination number of the $\mathrm{Au}-\mathrm{Au}$ pair of $\mathrm{Au}$ nuclei was evaluated to be 3 on the assumption that the coordination number of the $\mathrm{Au}-\mathrm{Au}$ pair is proportional to the amplitude of the EXAFS spectrum of the Au foil, the coordination number of which is 12. Therefore, the structure of the Au nuclei is estimated to be an $\mathrm{Au}_{4}$ cluster with a fcc crystal system, as shown in the inset of Figure 5. It should also be noted that almost all the $\mathrm{Au}$ atoms in the cell belong to the Au nuclei at $4.6 \mathrm{~s}$, because an XAFS spectrum provides information about the average state of an absorption atom. As far as we know, 
this is the first report of an observation of Au nuclei in the formation process of gold nanoparticles.

The series of $\mathrm{Au} L_{3}$ edge XANES spectra from $4.6 \mathrm{~s}$ to $178.6 \mathrm{~s}$ were fitted with the linear combination of the spectrum of the Au nuclei at $4.6 \mathrm{~s}$ and that of Au foil by using the least square method, which was verified by factor analysis. Figure 6 shows the time course of the fractions of the spectra of Au nuclei and foil resulting from the fitting. The fractions of the spectra of Au nuclei and foil respectively decreased and increased with time and approached to ca. 70 and 30\%. On the other hand, we calculated the XANES spectra of the surface, the inner atoms, and the whole of $\mathrm{Au}_{144}$ cluster protected by 60 of sulfur atoms as a model by using the FEFF 8.4 code. ${ }^{56}$ The XANES spectra of the inner Au atoms (Figure 7(c) and (d)) show two obvious peaks in the range from $11940 \mathrm{eV}$ to $11980 \mathrm{eV}$, which is similar to the spectrum of the Au foil (Figure 4). The surface Au atoms (Figure 7(a) and (b)) exhibit smoother spectra than the inner Au atoms, and have similar characteristics as that of the Au nuclei. The whole cluster represents an intermediate spectrum between the spectrum of the surface atoms and that of the inner atom. On the basis of the calculation results, we interpreted that the XANES spectra of the $\mathrm{Au}$ foil and the Au nuclei are those of the inner and surface atoms of gold nanoparticles, respectively. Thus, Figure 6 means the decrease of the fraction of the surface atoms and the increase of that of the inner atoms with reaction time; in other words, the growth of gold nanoparticles from Au nuclei.

The growth of gold nanoparticles in this synthesis system will proceed via the aggregation of the Au nuclei themselves, the Au clusters themselves, and/or both the Au nuclei and Au clusters, because the Au nuclei was observed by XAFS spectroscopy which provides information of average state of an absorption atom. Therefore, gold 
nanoparticles are formed by the reduction of all of $\mathrm{Au}$ ions, formation of nuclei, aggregation of the nuclei, and then the particles to grow larger. This proposal is different from the well known mechanisms, Finke-Watzky mechanism and LaMer mechanism (vide supra). ${ }^{18,19}$ Duff et al. analyzed the particle size distribution investigated by TEM to propose the combination/coalescence mechanism as a dominant particle growth mechanism. Their mechanism is compatible to our mechanism proposed by in situ analysis. $^{20}$ They applied $\mathrm{P}\left(\mathrm{CH}_{2} \mathrm{OH}\right)_{4} \mathrm{Cl}$ to a reductant for preparation of gold nanoparticles. $\mathrm{P}\left(\mathrm{CH}_{2} \mathrm{OH}\right)_{4} \mathrm{Cl}$ is a strong reducing agent to succeed in fast reduction of $\mathrm{Au}^{3+}$ to $\mathrm{Au}^{0}$ as well as $\mathrm{NaBH}_{4}$ used in this study. The fast reduction of $\mathrm{Au}^{3+}$ by strong reducing agents will produce Au nuclei, which aggregate to become larger.

\section{2. The size control mechanism of gold nanoparticles by tetradentate porphyrin ligand}

\section{4}

We applied the QXAFS analysis to clarify how the ligand 4, which efficiently provided small gold nanoparticles (vide supra), control the size of gold nanoparticles. ${ }^{57}$ As a control, the compound 5 having disulfide bond (Scheme 4) was utilized for the protecting ligand of gold nanoparticles. The Au $L_{3}$-edge XANES spectra of the DMF solution containing $\mathrm{HAuCl}_{4}$ in the presence of $\mathbf{4}$ or $\mathbf{5}$ at $\xi=1$ before the $\mathrm{NaBH}_{4}$ reduction showed a sharp and narrow absorption band at the edge, which were identical to that of the DMF solution of $\mathrm{HAuCl}_{4}$ (The XAFS spectrum of $\mathrm{HAuCl}_{4}$ in DMF was the same as that in toluene shown in Figure 4.). This result indicates that the protecting ligands having disulfide bond, $\mathbf{4}$ and $\mathbf{5}$, do not reduce $\mathrm{Au}^{3+}$ ions, although DT reduced $\mathrm{Au}^{3+}$ to $\mathrm{Au}^{+}$as described above (Figure 4). The addition of $\mathrm{NaBH}_{4}$ will reduce both $\mathrm{Au}^{3+}$ ions and disulfides $\mathbf{4}$ and $\mathbf{5}$ to the corresponding thiols $\mathbf{4}^{\prime}$ and $\mathbf{5}^{\prime}$, as represented in 
Scheme 4 . Note that $\mathbf{5}^{\prime}$ has a thiol group within the molecule; therefore, $\mathbf{5}$ virtually acts as a monodentate passivant. $\mathrm{NaBH}_{4}$ reduction gave rise to changes in both the XANES spectra of the solution containing $\mathrm{HAuCl}_{4}$ in the presence of $\mathbf{4}$ or $\mathbf{5}$. The variation of XANES spectra were similar to that of GN@DT (Figure 4), although the initial state of Au ions is different from that in the presence of DT: decrease in the intensity of white line; appearance of small shoulder peak at $11929 \mathrm{eV}$; approach to the spectra of Au foil. Therefore, GN@4 and $\mathbf{5}$ are formed by the same formation mechanism as GN@DT: reduction of all of $\mathrm{Au}$ ions; formation of small $\mathrm{Au}$ clusters; aggregation into nanoparticles.

Figure 8 shows that the XANES spectrum of Au nuclei in the presence of $\mathbf{4}$ and $\mathbf{5}$. The peak intensity of Au nuclei with $\mathbf{5}$ at $11929 \mathrm{eV}$ was slightly more intense compared with that observed for 4. On the other hand, the peak intensity at $11929 \mathrm{eV}$ decreases as the gold nanoparticles growing. In other words, the larger gold nanoparticles show the weaker absorption band around $11929 \mathrm{eV}$. Therefore, the weaker absorption band around $11929 \mathrm{eV}$ for $\mathbf{4}$ than $\mathbf{5}$ indicates that larger Au nuclei were formed by using $\mathbf{4}$ than 5. The formation of larger Au nuclei with 4 may originate from the low mobility and/or the steric hindrance of $\mathbf{4}$ because of the large molecular weight and rigidly directed thiol groups of $\mathbf{4}$, both of which result in less frequent collisions between the Au species and 4. Furthermore, the XANES analysis was performed at various $\xi$ values. As shown in Figure 8, the band at $11929 \mathrm{eV}$ for the Au nuclei prepared with 4 at $\xi=4$ was higher than that observed at $\xi=1$. Similarly, the Au nuclei prepared with $\mathbf{5}$ at $\xi=$ 0.1 showed a weaker band at $11929 \mathrm{eV}$ than that observed at $\xi=1$. Thus, the size of Au nuclei depends on the concentration and structure of the protective ligands, which implies that the size of Au nuclei is kinetically controlled by the speed with which the 
protecting ligands trap the growing Au nuclei.

The growth of gold nanoparticles was investigated by EXAFS. The Fourier-transformed EXAFS spectra (FT-EXAFS) of GN@4 after 5.6 s are shown in Figure 9. The height of bands from 1.8 to $3.2 \AA$, assigned to the Au-Au scatterings of Au metal, increased with the reaction time, indicating the growth of gold nanoparticles. For the formation of GN@5, similar changes were observed. The height at $2.68 \AA$ in the FT-EXAFS spectra is plotted against the reaction time in Figure 10. The height for GN@4 increased up to ca. $5 \AA^{-4}$ with increased reaction time while that for GN@5 increased up to ca. $6 \AA^{-4}$. Moreover, the initial rates of the increase in the FT height of GN@4 and GN@5 were estimated to be 0.66 and $0.72 \AA^{-4} \mathrm{~s}^{-1}$, respectively, by fitting the plots in Figure 10 with an exponential function. These results suggest that $\mathbf{4}$ suppresses the particle growth more efficiently than $\mathbf{5}$ to provide smaller gold nanoparticles. This difference is probably caused by the slow dissociation of $\mathbf{4}$ from the gold surface owing to its tight fixation through four Au-S bonds.

Scheme 5 shows the proposed formation mechanism of gold nanoparticles in the presence of passivants $\mathbf{4}$ and $\mathbf{5}$. Before the $\mathrm{NaBH}_{4}$ reduction, passivants $\mathbf{4}$ and $\mathbf{5}$ neither interact with nor reduce $\mathrm{Au}^{3+}$ ions. $\mathrm{NaBH}_{4}$ addition reduces $\mathrm{HAuCl}_{4}$ and the disulfide groups of $\mathbf{4}$ or $\mathbf{5}$. The $\mathrm{HAuCl}_{4}$ reduction leads to the dissociation of $\mathrm{Au}-\mathrm{Cl}$ bonds to form bare $\mathrm{Au}$ atoms and then small Au clusters. The reduced form of $\mathbf{4}$ or $\mathbf{5}$ traps the very small, growing Au nuclei. Thus, the size of the Au nuclei is kinetically controlled; 4 provides larger $\mathrm{Au}$ nuclei than $\mathbf{5}$ because of the low mobility of $\mathbf{4}$ and the rigidly directed $\mathrm{S}$ atoms of $\mathbf{4}$. However, these characteristics of $\mathbf{4}$ strongly suppress the growth of gold nanoparticles once 4 traps $\mathrm{Au}$ nuclei. Thus, this study demonstrates the importance of the structure of the passivants, which should provide a useful guideline 
for the future passivantbased design of gold nanoparticles.

\section{Photodeposition of $\mathrm{Rh}$ metal particles on $\mathrm{TiO}_{2}$}

In 1978, Bard et al. reported a new preparation method of metal nanoparticles on a photocatalyst utilizing photocatalytic reaction ${ }^{58}$ Photoirradiation to a photocatalyst (e.g., UV light irradiation to $\mathrm{TiO}_{2}$ ) generates electrons and holes on it. The electrons reduces metal cations which have more positive redox potential than the conduction band level of the photocatalyst, while the holes in the valence band are consumed to react with a sacrificial reagent such as alcohol, aldehyde, and carboxylic acid to promote the reduction reaction smoothly. As a result, metal particles are deposited on the photocatalyst. Thus, this metal deposition method is called photodeposition method. The metal modifying photocatalyst prepared by photodeposition often show higher photocatalytic activity than that prepared by the other conventional methods. Several papers reported that the photodeposited metal species modifing specific sites of a photocatalyst, e.g., an edge or plane of photocatalyst, and representing various morphology with properties and structures of photocatalyst. ${ }^{59,60}$ There should be unique interaction between metal and photocatalyst and formation mechanism of metal particles.

Herrmann's group has been investigated photodeposition mechanism on $\mathrm{TiO}_{2} ;$ Metal ions adsorb on $\mathrm{TiO}_{2}$ (1); Electron-hole pair in $\mathrm{TiO}_{2}$ is created by photoirradiation (2); The electron reduces metal ions to zerovalent metal atoms (3); Metal particles are formed through aggregation of individual zerovalent metal atoms (4a) or through cathodic-like reduction of metal ions on small metal nuclei (4b). ${ }^{61-65}$ 


$$
\begin{aligned}
& \mathrm{M}^{\mathrm{n}+}(\mathrm{s}) \rightleftharpoons \mathrm{M}^{\mathrm{n}+}(\mathrm{a}) \\
& \mathrm{TiO}_{2}+h n \rightarrow \mathrm{e}^{-}+\mathrm{h}^{+} \\
& \mathrm{M}^{\mathrm{n}+} \rightarrow \mathrm{M}^{0}(\mathrm{a}) \\
& \mathrm{mM}^{0}(\mathrm{a}) \rightarrow \mathrm{M}_{\mathrm{m}} \\
& +\mathrm{Mnn}^{+}+\mathrm{ne}-\mathrm{Mnn}^{+}+\mathrm{ne} \\
& \mathrm{M}_{0} \rightarrow \mathrm{M}_{2}{ }^{\mathrm{n+}} \rightarrow \mathrm{M}_{2}{ }^{0} \rightarrow \mathrm{M}_{3}{ }^{\mathrm{n+}} \rightarrow \mathrm{M}_{3}^{0} \rightarrow \cdots \rightarrow \mathrm{M}_{m}^{0}
\end{aligned}
$$

where $\mathrm{M}^{\mathrm{n}+}(\mathrm{s}), \mathrm{M}^{\mathrm{n}+}(\mathrm{a})$, and $\mathrm{M}^{0}(\mathrm{a})$, represents metal ions in solution, those adsorbed on $\mathrm{TiO}_{2}$, zerovalent metal atoms adsorbed on $\mathrm{TiO}_{2}$, respectively; $\mathrm{M}^{\mathrm{n}+}$ refers to $\mathrm{M}^{\mathrm{n}+}(\mathrm{s})$ or $\mathrm{M}^{\mathrm{n}+}(\mathrm{a}) ; \mathrm{M}_{\mathrm{m}}{ }^{\mathrm{n}+}$ and $\mathrm{M}_{\mathrm{m}}{ }^{0}$ present metal particle with metal ion and metal particle, respectively. It is known that the adsorption of metal ions represented by reaction (1) is Langmuir type. The generation of electron-hole pair (2) proceeds as described above. As for the reaction (3), Ferrnandez et al. analyzed a photodeposition in gas/solid interface by the in situ X-ray photoelectron spectroscopy (XPS). ${ }^{66}$ They presented that $\mathrm{Pt}^{4+}$ and $\mathrm{Rh}^{3+}$ ions were reduced to metal through $\mathrm{Pt}^{2+}$ and $\mathrm{Rh}^{+}$, while $\mathrm{Pd}^{2+}$ ions are reduced directly to metal. On the other hand, Ferrnandez et al. successfully observed the photodeposition process of $\mathrm{Au}$ particles on $\mathrm{TiO}_{2}$ by means of in situ X-ray absorption fine structure (XAFS) spectroscopy, although they could not clarify the photodeposition mechanism. The XAFS spectroscopy will be the most powerful tool to analyze photodeposition, because it can be applied without regard to the states of samples and provide information about the electronic state and the structure of absorption atom. ${ }^{62}$

In order to elucidate photodeposition mechanism, we studied the photodeposition of $\mathrm{Rh}$ metal particles on $\mathrm{TiO}_{2}$ by means of in situ energy dispersive XAFS (DXAFS) spectroscopy. ${ }^{45,67}$ Prior to an in situ XAFS analysis, a suspension containing $\mathrm{RhCl}_{3}$ and $\mathrm{TiO}_{2}$ was investigated. It is revealed that $\mathrm{Rh}^{3+}$ ions are adsorbed on $\mathrm{TiO}_{2}$ following a Langmuir type mechanism to form Rh-O bonds. ${ }^{67}$ Figure 11 shows a series of the FT of 
$k^{3}$-weighted Rh-K edge EXAFS spectra of Rh species for the photodeposition. The peak located at $1.73 \AA$ is assignable to the mixture of $\mathrm{Rh}-\mathrm{Cl}$ scattering of $\mathrm{RhCl}_{3}$ and $\mathrm{Rh}-\mathrm{O}$ scattering of $\mathrm{Rh}$ ions adsorbed on $\mathrm{TiO}_{2}$. The height of the peak at $1.73 \AA$ decreased with increasing photoirradiation time and an alternative peak appeared at $2.45 \AA$ which is evidently assigned to $\mathrm{Rh}-\mathrm{Rh}$ scattering of $\mathrm{Rh}$ metal particles generated by photoirradiation in comparison with the FT of EXAFS spectrum of Rh foil as a reference. The peak height at $2.45 \AA$ linearly rose with photoirradiation time and saturated after 90 min photoirradiation. Figure 12(a) demonstrates the photoirradiation time dependence of the coordination number ( $\mathrm{Rh}-\mathrm{Rh}$ pair) evaluated by the curve fitting of Rh-Rh scattering using empirical parameters extracted from the DXAFS spectrum of $\mathrm{Rh}$ foil. ${ }^{68}$ The coordination number increased proportionally to photoirradiation time, and it was evaluated to be 10 at $90 \mathrm{~min}$ of photoirradiation. On the other hand, the fractions of $\mathrm{Rh}$ metal particle and $\mathrm{Rh}^{3+}$ precursor were estimated by least-squares fitting of each XANES spectrum by linear combination of authentic spectra corresponding to $\mathrm{Rh}^{0}$ and $\mathrm{Rh}^{3+}$. The fraction of $\mathrm{Rh}$ metal linearly increased with photoirradiation time and saturated after 90 min photoirradiation as shown in Figure 12(b). Apparently, the behavior in Figure 12(b) is perfectly consistent with that in Figure 12(a). This result indicates that the intrinsic coordination number $(\mathrm{Rh}-\mathrm{Rh}$ pair) of generated $\mathrm{Rh}$ metal does not change during the photodeposition. In fact, the Debye-Waller factor does not undergo appreciable changes. The electrons generated by photoirradiation on $\mathrm{TiO}_{2}$ will reduce the $\mathrm{Rh}^{3+}$ ions to form $\mathrm{Rh}$ metal particles at a constant rate. At present, we suppose that Rh metal particles do not grow up in incremental steps but the Rh metal particles with a uniform size appear one after another on $\mathrm{TiO}_{2}$.

The $\mathrm{Rh}$ metal particles on $\mathrm{TiO}_{2}$ were observed using TEM, but they were not 
identified. ${ }^{69}$ On the other hand, energy dispersive X-ray spectroscopy (EDX) revealed that $\mathrm{Rh}$ metal species having a few dozen nanometers are deposited on $\mathrm{TiO}_{2}$. It is likely that the $\mathrm{Rh}$ metal have a disordered structure on $\mathrm{TiO}_{2}$. Interestingly, photodeposited $\mathrm{Pt}$ metal represented the same structure as the $\mathrm{Rh}$ metal, but $\mathrm{Au}$ metal showed clear particle boundary and spherical structure. It should be noted that $\mathrm{Rh}$ and $\mathrm{Pt}$ are group VIII metal and $\mathrm{Au}$ is not. The group VIII metal strongly interact with reducible metal oxide supports (e.g., $\mathrm{TiO}_{2}$ ) when the supports are reduced. ${ }^{70,71}$ The strong interaction between metal and supports (SMSI) influences on the electronic property and the morphology of metal particles, and causes the modification of metal particles with the reduced supports (e.g., $\mathrm{TiO}_{2-\delta}$ ). ${ }^{72-74}$ On the other hand, $\mathrm{TiO}_{2-\delta}$ can be generated by consumption of the photogenerated holes on $\mathrm{O}^{\delta+}$ of $\mathrm{TiO}_{2}$ without any reduction on $\mathrm{Ti}^{\delta-}{ }^{75} \mathrm{Ti}^{3+}$ in $\mathrm{TiO}_{2-\delta}$ contributes to an electron trap under the conduction band of $\mathrm{TiO}_{2}$, leading to a flow of excited electrons to $\mathrm{TiO}_{2-\delta}$ and a reduction of metal ions on $\mathrm{TiO}_{2-\delta}$. In fact, the defect sites were proposed as the active sites for formation of metal particles in the photodeposition process. ${ }^{76,77}$ Therefore, SMSI can occur during the photodeposition of group VIII metal on $\mathrm{TiO}_{2}$.

Figure 13 shows the $\mathrm{Rh} 3 \mathrm{~d}$ XPS. The peak of $\mathrm{Rh} 3 \mathrm{~d}_{5 / 2}$ XPS of photodeposited Rh metal on $\mathrm{TiO}_{2}$ appeared at $306.5 \mathrm{eV}$ (Figure 13(a)), which is of lower energy than that of $\mathrm{Rh}$ foil at $307.0 \mathrm{eV}$. This indicates that the surface of Rh metal photodeposited on $\mathrm{TiO}_{2}$ is more electron-rich than $\mathrm{Rh}$ foil. The peak energy of photodeposited $\mathrm{Rh}$ metal was also lower than $\mathrm{Rh} / \mathrm{TiO}_{2}$ in SMSI state which was prepared by impregnation method and reduced at $773 \mathrm{~K}$. The ideal condition for SMSI may thus be provided in the photodeposition process. The $\mathrm{Rh}$ metal photodeposited on $\mathrm{TiO}_{2}$ was sputtered by $\mathrm{Xe}$ ion and the composition ratio between $\mathrm{Rh}$ and $\mathrm{Ti}(\mathrm{Rh} / \mathrm{Ti}$ ratio) at a given sputtering time 
was evaluated from those peak areas divided by respective atomic sensitivity factors. Figure 14 shows the variation in $\mathrm{Rh} / \mathrm{Ti}$ ratio with sputtering time of $\mathrm{Rh}$ metal photodeposited on $\mathrm{TiO}_{2}$. The $\mathrm{Rh} / \mathrm{Ti}$ ratio increased as the sputtering time increased, and approached $1.4 \%$ after $10 \mathrm{~min}$. The two structural models of Rh metal photodeposited on $\mathrm{TiO}_{2}$ are assumed from the depth profile. One is that $\mathrm{Rh}$ metal particles having a size comparable to $\mathrm{TiO}_{2}$ particles are modified by their interaction with $\mathrm{TiO}_{2}$. The other is that the $\mathrm{Rh}$ species is intermixed with a $\mathrm{TiO}_{2}$ particle. The EDX analysis reveals that the Rh metal particles have almost the same size as that of $\mathrm{TiO}_{2}$ (ca. $15 \mathrm{~nm}$ ). Thus, we proposed the first model as the structure of $\mathrm{Rh}$ metal modifying $\mathrm{TiO}_{2}$ prepared by photodeposition (Figure 15).

The in situ XAFS study suggested the photodeposition mechanism as follows; the Langmuir type adsorption of $\mathrm{Rh}^{3+}$ ions on $\mathrm{TiO}_{2}$ to form $\mathrm{Rh}-\mathrm{O}$ bonds; the reduction of $\mathrm{Rh}^{3+}$ ions to $\mathrm{Rh}$ metals on the surface of irradiated $\mathrm{TiO}_{2}$; the constant appearance of $\mathrm{Rh}$ metal particles. The average coordination number ( $\mathrm{Rh}-\mathrm{Rh}$ pair) was ca. 10, which indicates the formation of $\mathrm{Rh}$ particles with ca. $2-3 \mathrm{~nm}$ assuming the cuboctahedral structure. On the other hand, TEM, EDS, and XPS study proposed that the Rh metal particles with ca. $15 \mathrm{~nm}$ of domain strongly interact with $\mathrm{TiO}_{2}$ (more specifically with $\mathrm{TiO}_{2-\delta}$ ) to form disordered structure. In addition, the $\mathrm{Rh}$ particles were modified by $\mathrm{TiO}_{2-\delta}$. From these results, we now assume that $\mathrm{Rh}$ metal particles having ca. $2-3 \mathrm{~nm}$ constantly appear and aggregate to form a disordered structure due to the SMSI and modification with $\mathrm{TiO}_{2}$.

\section{Conclusion}

We developed size controlled synthesis of metal nanoparticles and focused attention on 
formation mechanisms of metal nanoparticles in two useful synthesis systems. The first system is wet chemical synthesis of gold nanoparticles by fast reduction of Au ions. Small gold nanoparticles, $2-5 \mathrm{~nm}$ in size, were effectively synthesized by designing the structure of protecting ligand, porphyrin ligand having four sulfur atoms. In situ QXAFS study revealed that the gold nanoparticles are generated through reduction of $\mathrm{Au}$ ions, nucleation and then aggregation. Protecting ligands kinetically trap the growing gold clusters in the early stage of particle formation, and suppress the growth of gold nanoparticles not only kinetically but also thermodynamically. Therefore, the structure, bulkiness and alignment of functional groups of protecting ligand affects on the resulting particle size. The second system described in this paper is photodeposition of metal nanoparticles on photocatalyst. $\mathrm{Rh}$ nanoparticles having uniform size were formed on $\mathrm{TiO}_{2}$, while the resulting $\mathrm{Rh}$ nanoparticles strongly interact with photocatalyst. The interaction between $\mathrm{Rh}$ and $\mathrm{TiO}_{2}$ affects on the morphology of $\mathrm{Rh}$ nanoparticles. These findings will help to understand metal nanoparticles modifying photocatalysts. Further study on particle formation mechanism will give the guideline to design metal nanoparticles and their peculiar properties.

\section{ACKNOWLEDGMENT.}

This study was supported by the Program for Improvement of Research Environment for Young Researchers from Special Coordination Funds for Promoting Science and Technology (SCF) commissioned by the Ministry of Education, Culture, Sports, Science and Technology (MEXT) of Japan, and Grants-in-Aid for Scientific Research (B) (No. 22360338) and Young Scientists (B) (Nos. 17750156 and 20750135) from the MEXT of Japan. The authors thank Mr. Shin-ichi Okuoka, Mr. Yasuhiro Higuchi, and 
Mr. Akira Yamamoto at Kyoto University for the collaboration to the synthesis and XAFS study. The authors are deeply grateful to Prof. Tetsuya Shishido at Kyoto University for his fruitful discussions and worthy suggestions. The XAFS measurements at the SPring- 8 were carried out by the approval (proposal Nos. 2007A1921, 2007B1094, 2008A1101, 2008A1102, 2009A1663, and 2009B1712) of Japan Synchrotron Radiation Research Institute (JASRI). 
FIGURE CAPTIONS.

Figure 1. TEM images of GN@1 (a) and GN@2 (b) with histograms of particle size in the right. The initial $\mathrm{S}$ to Au ratio $=1$ for both cases.

Figure 2. Plots of the mean diameter of gold nanoparticles against the initial $\mathrm{S}$ to $\mathrm{Au}$ ratio.

Figure 3. Mean diameter plots of gold nanoparticles GN@3 (square) and GN@4 (circle) against the initial $\mathrm{S}$ to Au ratio.

Figure 4. Series of $\mathrm{Au} \mathrm{L}_{3}$-edge XANES spectra during the formation of gold nanoparticle in the presence of the equimolar of DT to $\mathrm{HAuCl}_{4}$ from $0 \mathrm{~s}$ to $178.5 \mathrm{~s}$ (solid line). The spectra vary from the top to the bottom region with an increase in time. References: [TOA] $\mathrm{AuCl}_{4}$ (dotted line), $\mathrm{Au}$ foil (dashed line), $\mathrm{Au}_{11}\left(\mathrm{PPh}_{3}\right)_{8} \mathrm{Cl}_{3}$ (dashed dotted line), and [TOA] $\mathrm{AuCl}_{2}$ (dashed double-dotted line).

Figure 5. EXAFS spectrum of Au nuclei observed during gold nanoparticle formation.

(a) EXAFS spectrum of Au nuclei observed at $4.6 \mathrm{~s}$ after the addition of $\mathrm{NaBH}_{4}$ to the $\mathrm{HAuCl}_{4}$ solution. (b) The simulated spectrum by linear combination of the reference spectra of (c) $12.5 \%$ of the solution of DT/Au $=1$ before reduction and (d) $25 \%$ of the Au foil. The 7.5-11 and 13-15 $\AA^{-1} k$ ranges where the oscillations of (c) and (d) are in phase are in gray. The inset is the estimated structure of Au nuclei from the linear combination, an $\mathrm{Au}_{4}$ cluster with fcc crystal system. 
Figure 6. Time course of the fractions of the surface and inner atoms of gold nanoparticles. The fraction of the XANES spectrum of Au nuclei observed at $4.6 \mathrm{~s}$ during the formation of gold nanoparticles, representing that of the surface atoms of nanoparticle (circle). The fraction of the XANES spectrum of the Au foil representing that of the inner atoms (square). The fractions were evaluated by least-squares fitting of the series of XANES spectra with a linear combination of the spectra of the Au nuclei and $\mathrm{Au}$ foil. The resulting $\mathrm{R}$ factor (triangle).

Figure 7. Calculated XANES spectra of the surface (solid line), and inner Au atoms (dotted line) of $\mathrm{Au}_{144}$ cluster protected by 60 of $\mathrm{S}$ atoms (insert; $\mathrm{Au}$ : gray, S: black), together with the entire cluster (dashed line). (a) The outermost atom having two Au-S bonds. (b) The second-outermost atom having one Au-S bond. (c) The second-innermost atom having 12 of $\mathrm{Au}-\mathrm{Au}$ bonds. (d) The innermost atom having 11 of $\mathrm{Au}-\mathrm{Au}$ bonds.

Figure 8. XANES spectra of Au nuclei in the presence of $\mathbf{4}$ at $\xi=1$ (a), 5 at $\xi=1$ (b), 4 at $\xi=4(\mathrm{c})$, and $\mathbf{5}$ at $\xi=0.1(\mathrm{~d})$.

Figure 9. Series of FT- of $k^{3}$ weighted EXAFS spectra during the GN@4 formation together with the Au foil spectrum (thin dashed-dotted). (Bold solid: $5.6 \mathrm{~s}$, bold dotted: 9.5 s, bold dashed: 14.5 s, bold dashed-dotted: 24.5 s, thin solid: 39.4 s, thin dotted: 79.6 s, thin dashed: $178.5 \mathrm{~s}$ ). The error of data points were $0.18 \AA^{-4}$ based on window width and truncation of the $k^{3} \chi(\mathrm{k})$ data for the Fourier transformation. 
Figure 10. Height of FT of EXAFS spectra at $2.68 \AA$ for GN@4 (circle) and GN@5 (triangle) against reaction time after the formation of Au nuclei.

Figure 11. Series of the FT of $k^{3}$-weighted Rh-K edge EXAFS spectra of Rh species for the photodeposition.

Figure 12. Photoirradiation time dependence of the coordination number ( $\mathrm{Rh}-\mathrm{Rh}$ pair) (circle) (a) and the fractions of $\mathrm{Rh}$ metal (triangle) (b).

Figure 13. $\mathrm{Rh} 3 \mathrm{~d}$ XPS spectra of $\mathrm{Rh}$ metal photodeposited on $\mathrm{TiO}_{2}$ (a) and $\mathrm{Rh}$ metal in SMSI state on $\mathrm{TiO}_{2}(\mathrm{~b})$.

Figure 14. The change in $\mathrm{Rh} / \mathrm{Ti}$ ratio of photodeposited $\mathrm{Rh}$ metal on $\mathrm{TiO}_{2}$ by $\mathrm{Xe}$ sputtering for $10 \mathrm{~min}$.

Figure 15. Proposed structure of $\mathrm{Rh}$ metal nanoparticles photodeposited on $\mathrm{TiO}_{2}$. 
SCHEME TITLES.

Scheme 1. Brief formation mechanism of metal nanoparticles.

Scheme 2. Structures of tetradentate and monodentate protecting ligands, 1 and 2.

Scheme 3 Structures of porphyrin-based protecting ligands, 3 and 4.

Scheme 4 Formation of thiols 4' and 5' corresponding to disulfides 4 and 5, respectively, by $\mathrm{NaBH}_{4}$ reduction.

Scheme 5 Formation mechanism of gold nanoparticles in the presence of tetradentate ligand $\mathbf{4}$ and monodentate ligand $\mathbf{5 .}$ 


\section{REFERANCES.}

(1) Haruta, M. Catalysis Today 1997, 36, 153-166

(2) Kamat, P. V. J. Phys. Chem. B 2002, 106, 7729-7744.

(3) Hu, M.; Chen, J.; Li, Z.-Y.; Au, L.; Hartland, G. V.; Li, X.; Marquez, M.; Xia, Y. Chem. Soc. Rev. 2006, 35, 1084-1094.

(4) Hori, H.; Teranishi, T.; Nakae, Y.; Seino, Y.; Miyake, M.; Yamada, S. Phys. Lett. A 1999, 263, 406-410.

(5) Blatchford, C. G.; Campbell, J. R.; Creighton, J. A. Surf. Sci. 1982, 120, 435-455.

(6) Toshima, N.; Yonezawa, T. New J. Chem. 1998, 22, 1179-1201.

(7) Hirai, H.; Nakao, Y.; Toshima, N. Chem. Lett. 1978, 545-548.

(8) Lu, P.; Teranishi, T.; Asakura, K.; Miyake, M.; Toshima, N. J. Phys. Chem. B 1999, $103,9673-9682$.

(9) Hirai, H.; Nakao, Y.; Toshima, N. J. Macromol. Sci. Chem. 1979, A13, 727-750.

(10) Fievet, F.; Lagier, J. P.; Blin, B.; Beaudoin, B.; Figlarz, M. Solid State Ionics 1989, 32-33, 198-205.

(11) Bonnemann, H.; Richards, R. M. Eur. J. Inorg. Chem. 2001, 2455-2480.

(12) Brust, M.; Walker, M.; Bethell, D.; Schiffrin, D. J.; Whyman, R. J. Chem. Soc., Chem. Commun. 1994, 801.

(13) Toshima, N.; Takahashi, T.; Hirai, H. Chem. Lett. 1985, 1245-1248.

(14) Glockler, J.; Klutzke, S.; Meyer-Zaika, W.; Reller, A.; Garcia-Garcia, F. J.; Strehblow, H. H.; Keller, P.; Rentschler, E.; Klaui, W. Angew. Chem. Int. Ed. 2007, 46, 1164-1167.

(15) Pelzer, K.; Vidoni, O.; Philippot, K.; Chaudret, B.; Colliere, V. Adv. Funct. Mater. 2003, 13, 118-126.

(16) Schmid, G. Chem. Rev. 1992, 92, 1709-1727.

(17) Jin, R. C. Nanoscale 2010, 2, 343-362.

(18) LaMer, V. K.; Dinegar, R. H. J. Am. Chem. Soc. 1950, 72, 4847-4854.

(19) Watzky, M. A.; Finke, R. G. J. Am. Chem. Soc. 1997, 119, 10382-10400.

(20) Duff, D. G.; Baiker, A.; Edwards, P. P. Langmuir 1993, 9, 2301-2309.

(21) Leff, D. V.; Ohara, P. C.; Heath, J. R.; Gelbart, W. M. J. Phys. Chem. 1995, 99, 7036-7041.

(22) Matijevic, E. Chem. Mater. 1993, 5, 412-426.

(23) Look, J. L.; Bogush, G. H.; Zukoski, C. F. Faraday Discuss. 1990, 345-357.

(24) Shevchenko, E. V.; Talapin, D. V.; Schnablegger, H.; Kornowski, A.; Festin, O.; Svedlindh, P.; Haase, M.; Weller, H. J. Am. Chem. Soc. 2003, 125, 9090-9101.

(25) Teranishi, T.; Kiyokawa, I.; Miyake, M. Adv. Mater. 1998, 10, 596-+.

(26) Teranishi, T.; Hosoe, M.; Tanaka, T.; Miyake, M. J. Phys. Chem. B 1999, 103, 
3818-3827.

(27) Teranishi, T.; Miyake, M. Chem. Mater. 1998, 10, 594-600.

(28) Teranishi, T.; Kiyokawa, I.; Miyake, M. Advanced Materials 1998, 10, 596-+.

(29) Hostetler, M. J.; Wingate, J. E.; Zhong, C.-J.; Harris, J. E.; Vachet, R. W.; Clark, M. R.; Londono, J. D.; Green, S. J.; Stokes, J. J.; Wignall, G. D.; Glish, G. L.; Porter, M. D.; Evans, N. D.; Murray, R. W. Langmuir 1998, 14, 17-30.

(30) Hyeon, T.; Lee, S. S.; Park, J.; Chung, Y.; Na, H. B. J. Am. Chem. Soc. 2001, 123, 12798-12801.

(31) Peterle, T.; Leifert, A.; Timper, J.; Sologubenko, A.; Simon, U.; Mayor, M. Chem. Commun. 2008, 3438-3440.

(32) Jin, R.; Qian, H.; Wu, Z.; Zhu, Y.; Zhu, M.; Mohanty, A.; Garg, N. J. Phys. Chem. Lett. 2010, 1, 2903-2910.

(33) Ohyama, J.; Hitomi, Y.; Higuchi, Y.; Shinagawa, M.; Mukai, H.; Kodera, M.; Teramura, K.; Shishido, T.; Tanaka, T. Chem. Commun. 2008, 6300-6302.

(34) Collman, J. P.; Gagne, R. R.; Reed, C.; Halbert, T. R.; Lang, G.; Robinson, W. T. J. Am. Chem. Soc. 1975, 97, 1427-1439.

(35) Zhang, S. S.; Leem, G.; Srisombat, L. O.; Lee, T. R. J. Am. Chem. Soc. 2008, 130, $113-120$.

(36) Yamada, M.; Kuzume, A.; Kurihara, M.; Kubo, K.; Nishihara, H. Chem. Commun. 2001, 2476-2477.

(37) Frenkel, A. I.; Nemzer, S.; Pister, I.; Soussan, L.; Harris, T.; Sun, Y.; Rafailovich, M. H. J. Chem. Phys. 2005, 123, 184701-184706.

(38) Takahashi, H.; Kanehara, M.; Teranishi, T. J. Photopoly. Sci. Technol. 2007, 20, $133-135$

(39) Barber, D. C.; Freitagbeeston, R. A.; Whitten, D. G. J. Phys. Chem. 1991, 95, 4074-4086.

(40) Yonezawa, T.; Yasui, K.; Kimizuka, N. Langmuir 2001, 17, 271-273.

(41) Tour, J. M.; Jones, L.; Pearson, D. L.; Lamba, J. J. S.; Burgin, T. P.; Whitesides, G. M.; Allara, D. L.; Parikh, A. N.; Atre, S. J. Am. Chem. Soc. 1995, 117, 9529-9534.

(42) Bethencourt, M. I.; Srisombat, L.-o.; Chinwangso, P.; Lee, T. R. Langmuir 2009, 25, $1265-1271$.

(43) Hitomi, Y.; Ohyama, J.; Higuchi, Y.; Aoki, K.; Shishido, T.; Funabiki, T.; Kodera, M.; Tanaka, T. Bull. Chem. Soc. Jpn. 2010, 83, 1392.

(44) Shishido, T.; Asakura, H.; Amano, F.; Sone, T.; Yamazoe, S.; Kato, K.; Teramura, K.; Tanaka, T. Catal. Lett. 2009, 131, 413-418.

(45) Teramura, K.; Okuoka, S.-i.; Yamazoe, S.; Kato, K.; Shishido, T.; Tanaka, T. J. Phys. 
Chem. C 2008, 112, 8495-8498.

(46) Okumura, K.; Nota, K.; Yoshida, K.; Niwa, M. J. Catal. 2005, 231, 245-253.

(47) Okumura, K.; Kusakabe, T.; Yokota, S.; Kato, K.; Tanida, H.; Uruga, T.; Niwa, M. Chem. Lett. 2003, 32, 636-637.

(48) Harada, M.; Inada, Y. Langmuir 2009, 25, 6049-6061.

(49) Suzuki, A.; Inada, Y.; Yamaguchi, A.; Chihara, T.; Yuasa, M.; Nomura, M.; Iwasawa, Y. Angewandte Chemie-International Edition 2003, 42, 4795-4799.

(50) Nishimura, S.; Mott, D.; Takagaki, A.; Maenosono, S.; Ebitani, K. Phys. Chem. Chem. Phys. 2011, 13, 9335-9343.

(51) Nishimura, S.; Takagaki, A.; Maenosono, S.; Ebitani, K. Langmuir 2009, 26, 4473-4479.

(52) Polte, J.; Ahner, T. T.; Delissen, F.; Sokolov, S.; Emmerling, F.; Thunemann, A. F.; Kraehnert, R. J. Am. Chem. Soc. 2010, 132, 1296-1301.

(53) Uruga, T.; Tanida, H.; Inoue, K.; Yamazaki, H.; Irie, T. AIP Conf. Proc. 2007, 882, 914-916.

(54) Ohyama, J.; Teramura, K.; Higuchi, Y.; Shishido, T.; Hitomi, Y.; Kato, K.; Tanida, H.; Uruga, T.; Tanaka, T. ChemPhysChem 2011, 12, 127-131.

(55) Woehrle, G. H.; Warner, M. G.; Hutchison, J. E. J. Phys. Chem. B 2002, 106, 9979-9981.

(56) Ankudinov, A. L.; Ravel, B.; Rehr, J. J.; Conradson, S. D. Physical Review B 1998, $58,7565-7576$

(57) Ohyama, J.; Teramura, K.; Higuchi, Y.; Shishido, T.; Hitomi, Y.; Aoki, K.; Funabiki, T.; Kodera, M.; Kato, K.; Tanida, H.; Uruga, T.; Tanaka, T. Phys. Chem. Chem. Phys. 2011, 13, 11128-11135

(58) Kraeutler, B.; Bard, A. J. J. Am. Chem. Soc. 1978, 100, 4317-4318.

(59) Tsuji, I.; Kato, H.; Kobayashi, H.; Kudo, A. J. Am. Chem. Soc. 2004, 126, $13406-13413$

(60) Tsuji, I.; Kato, H.; Kobayashi, H.; Kudo, A. J. Phys. Chem. B 2005, 109, 7323-7329.

(61) Caballero, A.; Gonzalezelipe, A. R.; Fernandez, A.; Herrmann, J. M.; Dexpert, H.; Villain, F. J. Photochem. Photobiol. A: Chem. 1994, 78, 169-172.

(62) Fernandez, A.; Caballero, A.; Gonzalez-Elipe, A. R.; Herrmann, J.-M.; Dexpert, H.; Villain, F. J. Phys. Chem. 1995, 99, 3303-3309.

(63) Herrmann, J. M.; Disdier, J.; Pichat, P. J. Phys. Chem. 2002, 90, 6028-6034.

(64) Herrmann, J.-M.; Disdier, J.; Pichat, P. J. Catal. 1988, 113, 72-81.

(65) Herrmann, J.-M.; Mansot, J.-L. J. Catal. 1990, 121, 340-348.

(66) Fernandez, A.; Gonzalez-Elipe, A. R. Appl. Surf. Sci. 1993, 69, 285-289. 
(67) Ohyama, J.; Teramura, K.; Okuoka, S.-i.; Yamazoe, S.; Kato, K.; Shishido, T.; Tanaka, T. Langmuir 2010, 26, 13907-13912.

(68) Data reduction was performed using REX2000 program Ver. 2.59 (Rigaku Corp.).

(69) Ohyama, J.; Yamamoto, A.; Teramura, K.; Shishido, T.; Tanaka, T. ACS Catal. 2011, 1, 187-192.

(70) Tauster, S. J.; Fung, S. C.; Baker, R. T. K.; Horsley, J. A. Science 1981, 211, 1121-1125.

(71) Tauster, S. J.; Fung, S. C.; Garten, R. L. J. Am. Chem. Soc. 1978, 100, 170-175.

(72) Fung, S. C. J. Catal. 1982, 76, 225-230.

(73) Baker, R. T. K.; Prestridge, E. B.; Garten, R. L. J. Catal. 1979, 59, 293-302.

(74) Fu, Q.; Wagner, T.; Olliges, S.; Carstanjen, H. D. J. Phys. Chem. B 2005, 109, 944-951.

(75) Takeuchi, M.; Deguchi, J.; Sakai, S.; Anpo, M. Appl. Catal. B 2010, 96, 218-223.

(76) Kowalska, E.; Abe, R.; Ohtani, B. Chem. Commun. 2009, 241-243.

(77) Wahlstrom, E.; Lopez, N.; Schaub, R.; Thostrup, P.; Ronnau, A.; Africh, C.; Legsgaard, E.; Norskov, J. K.; Besenbacher, F. Phys. Rev. Lett. 2003, 90, 026101. 
FIGURES.

(a)

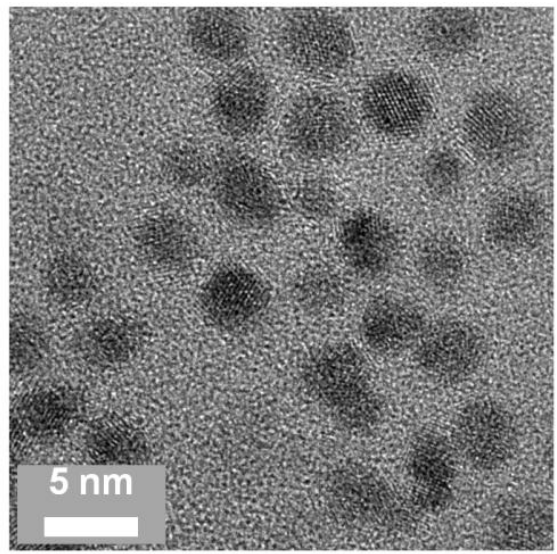

$3.5 \pm 0.7 \mathrm{~nm}$

(b)
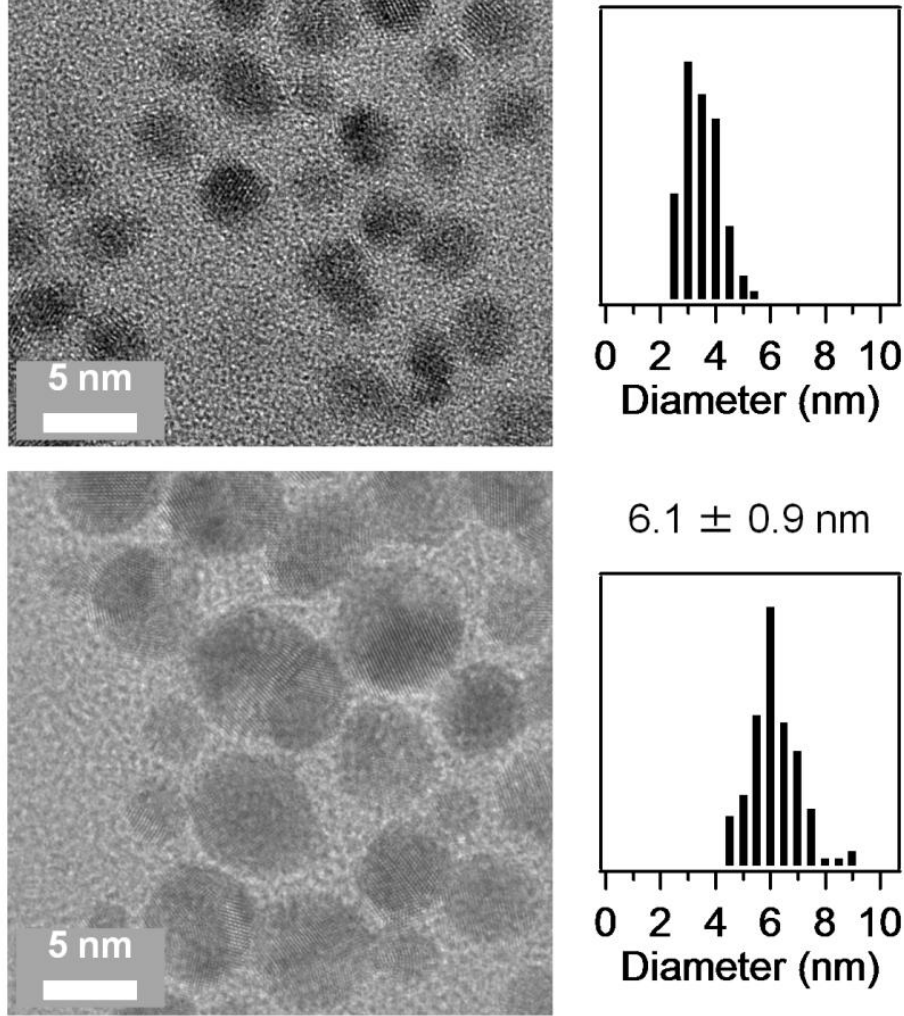

$6.1 \pm 0.9 \mathrm{~nm}$

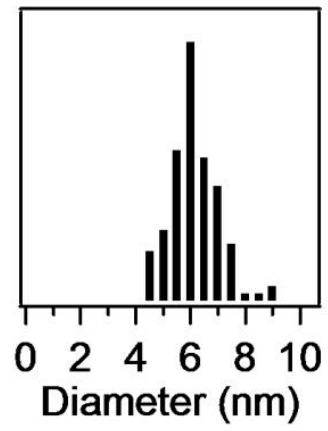

Figure1 


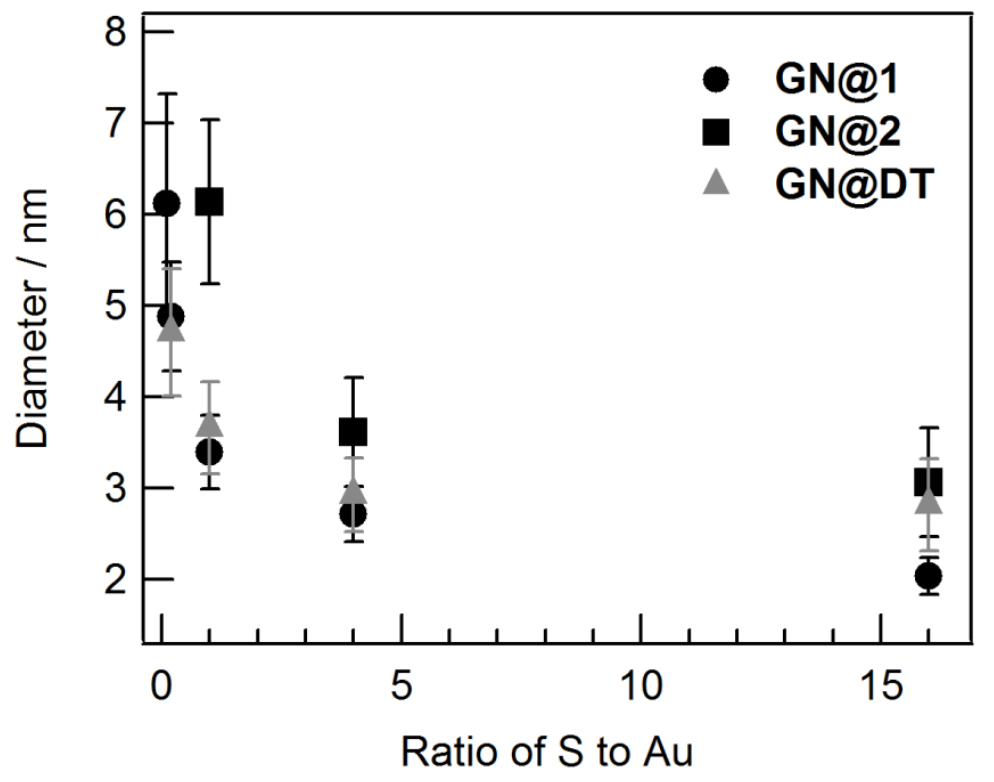

Figure 2

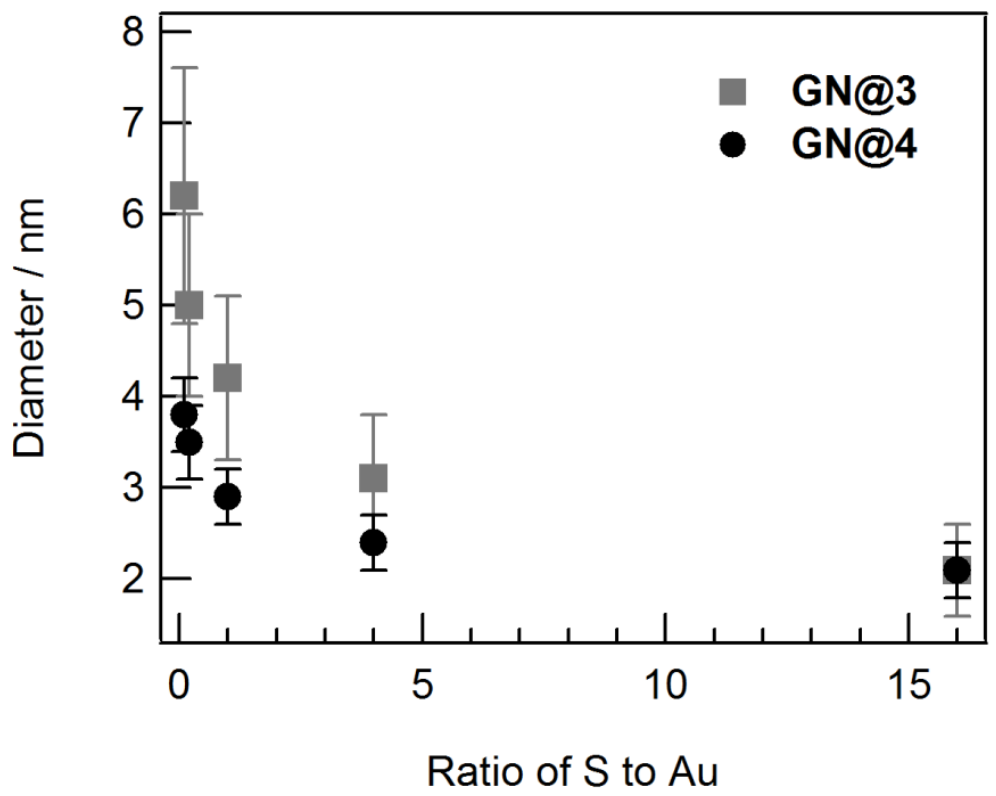

Figure 3 


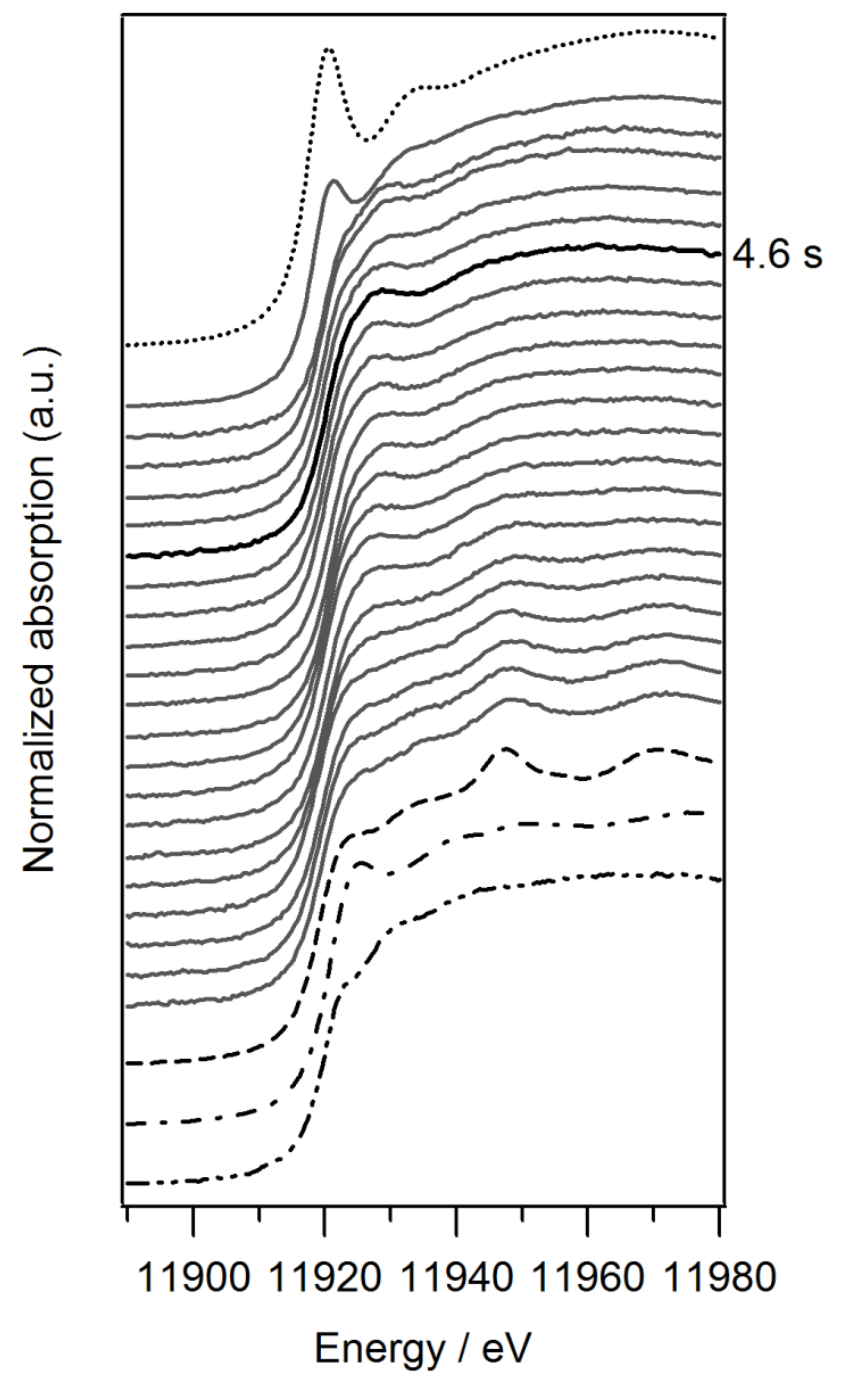

Figure 4 


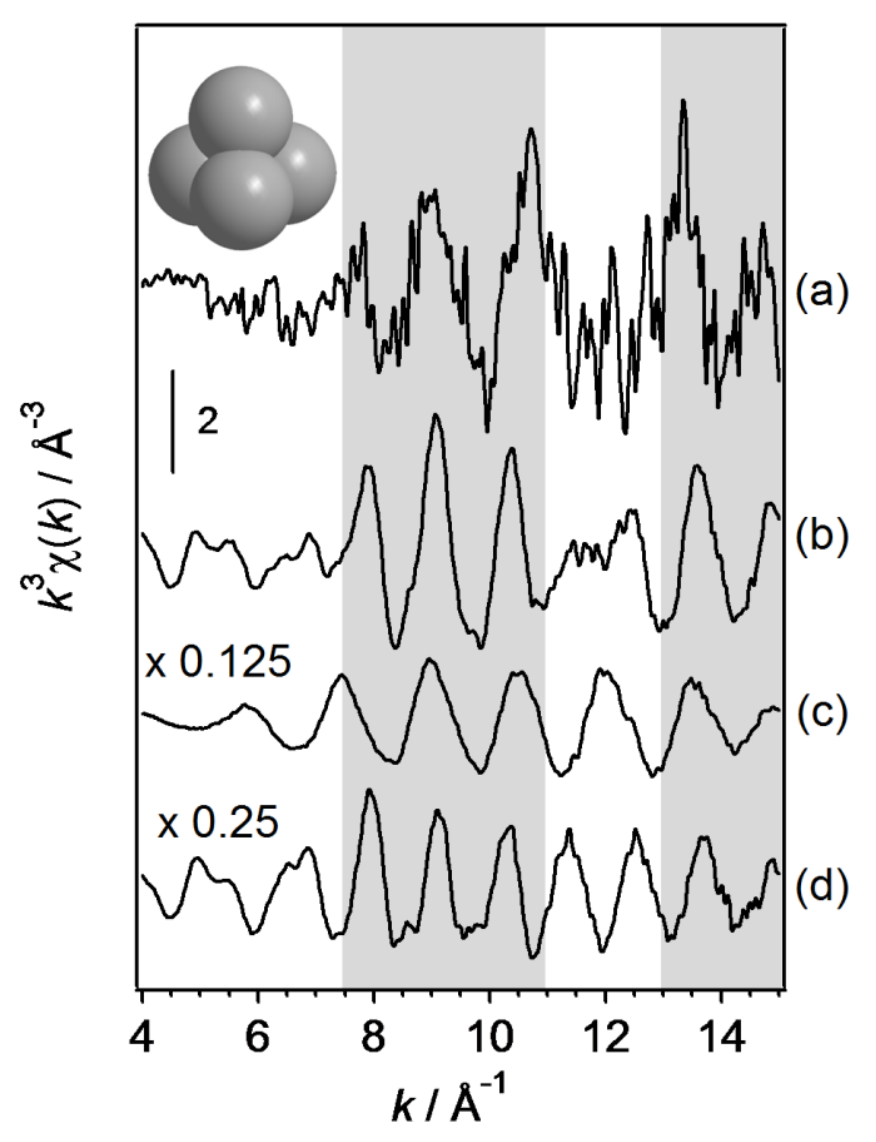

Figure 5 


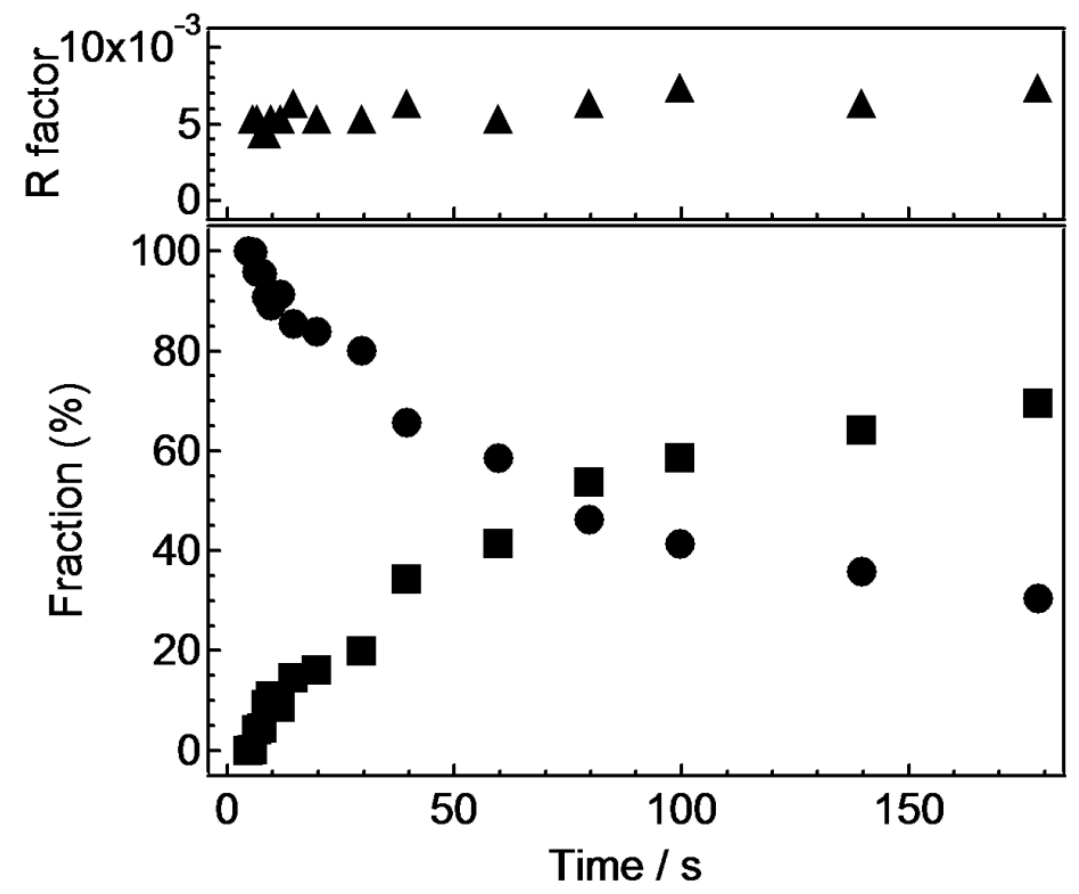

Figure 6 


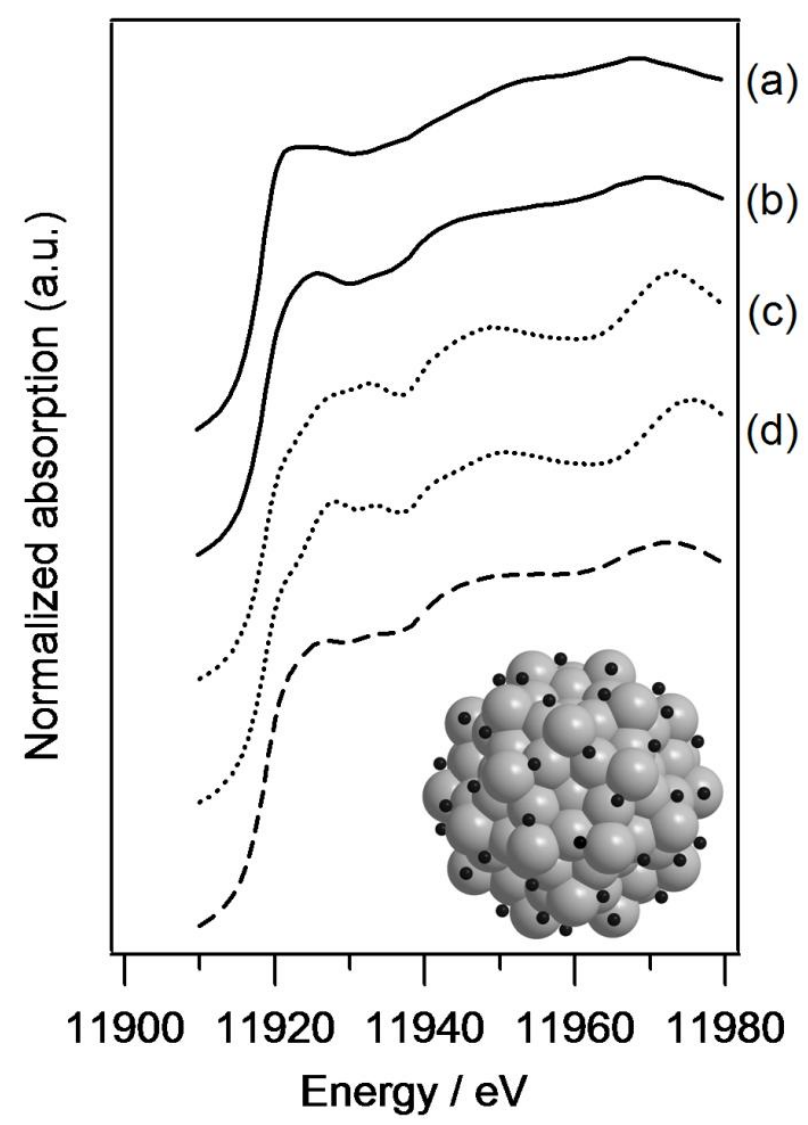

Figure 7 


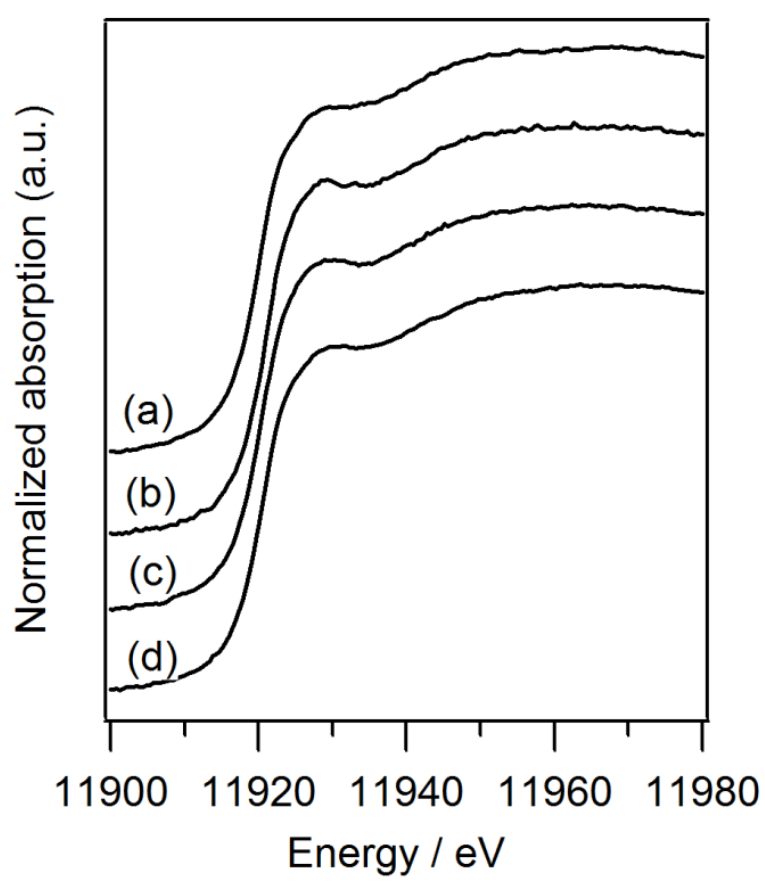

Figure 8 


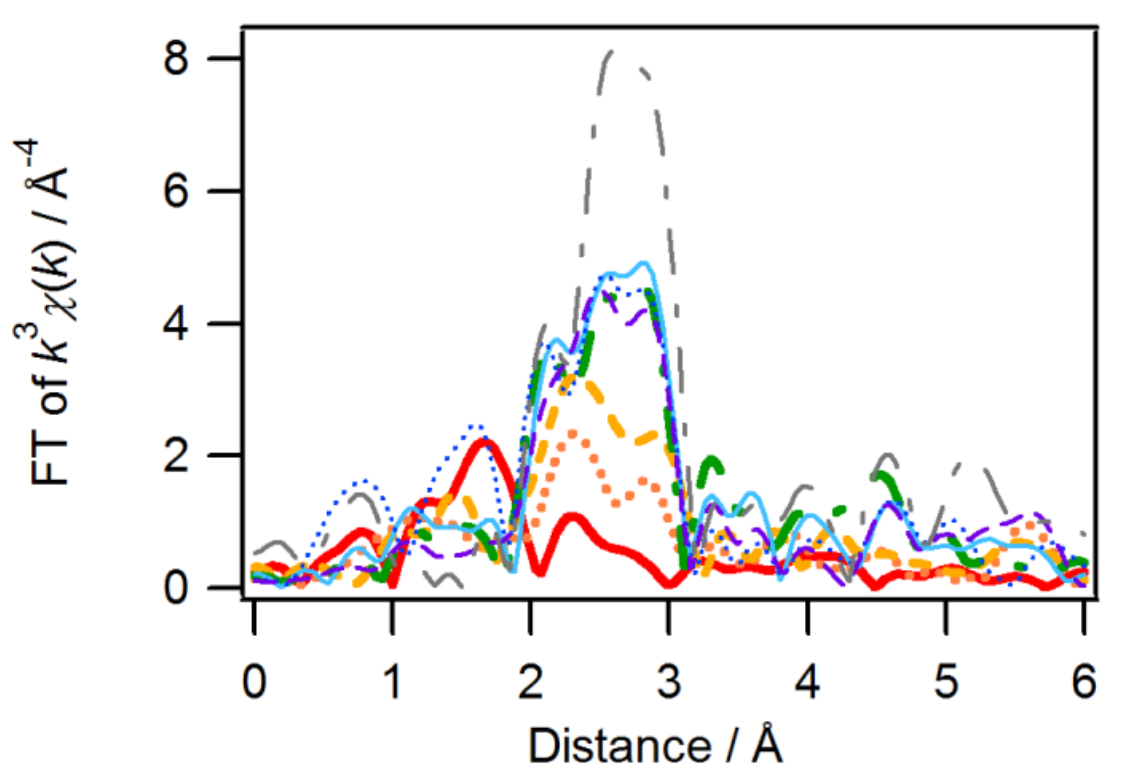

Figure 9 


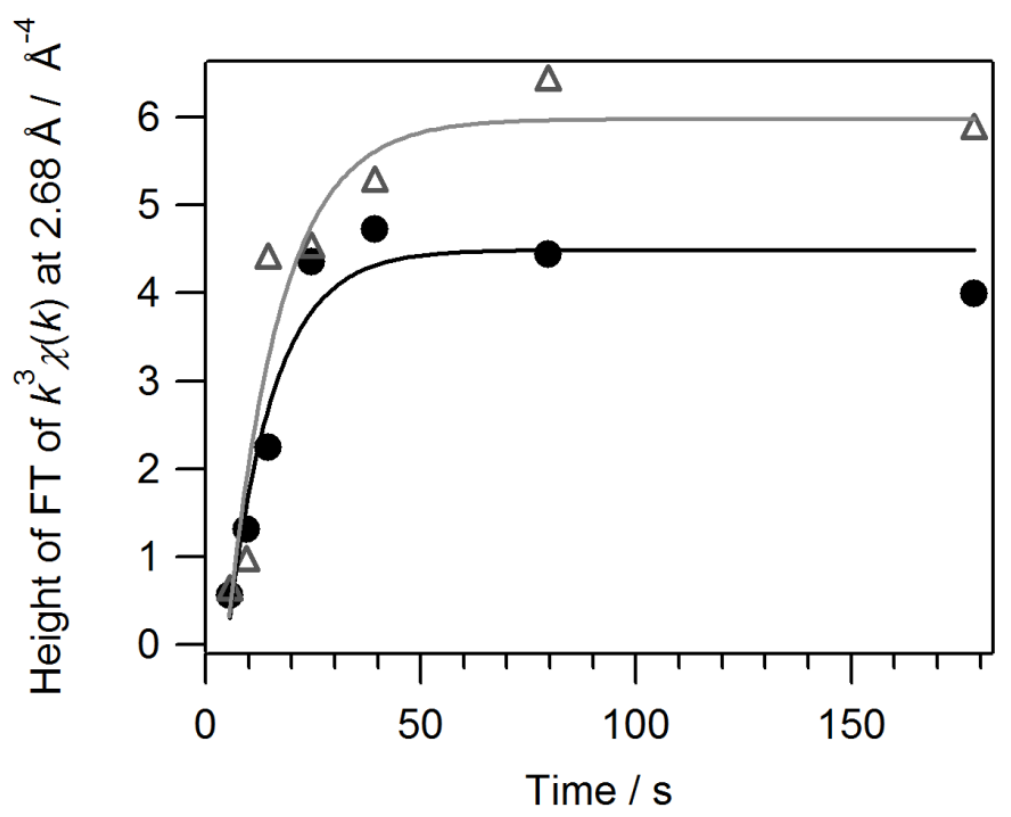

Figure 10 


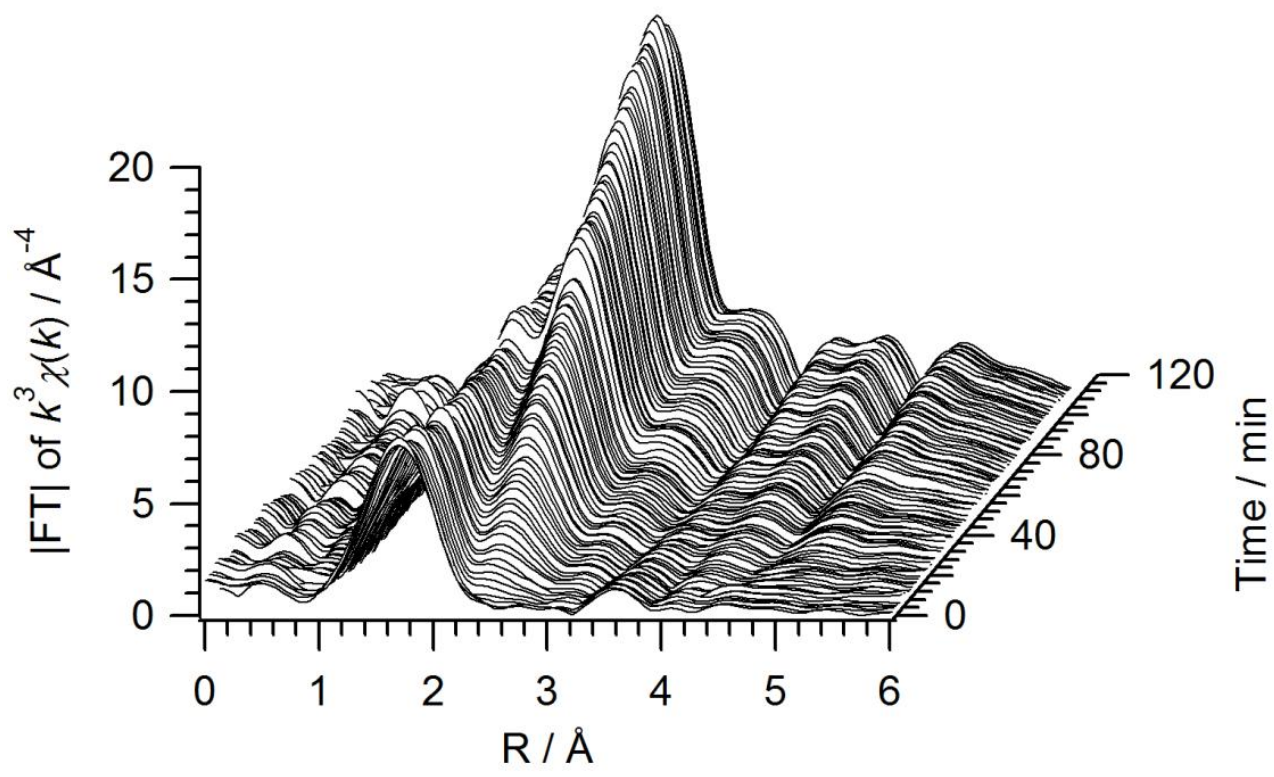

Figure 11 


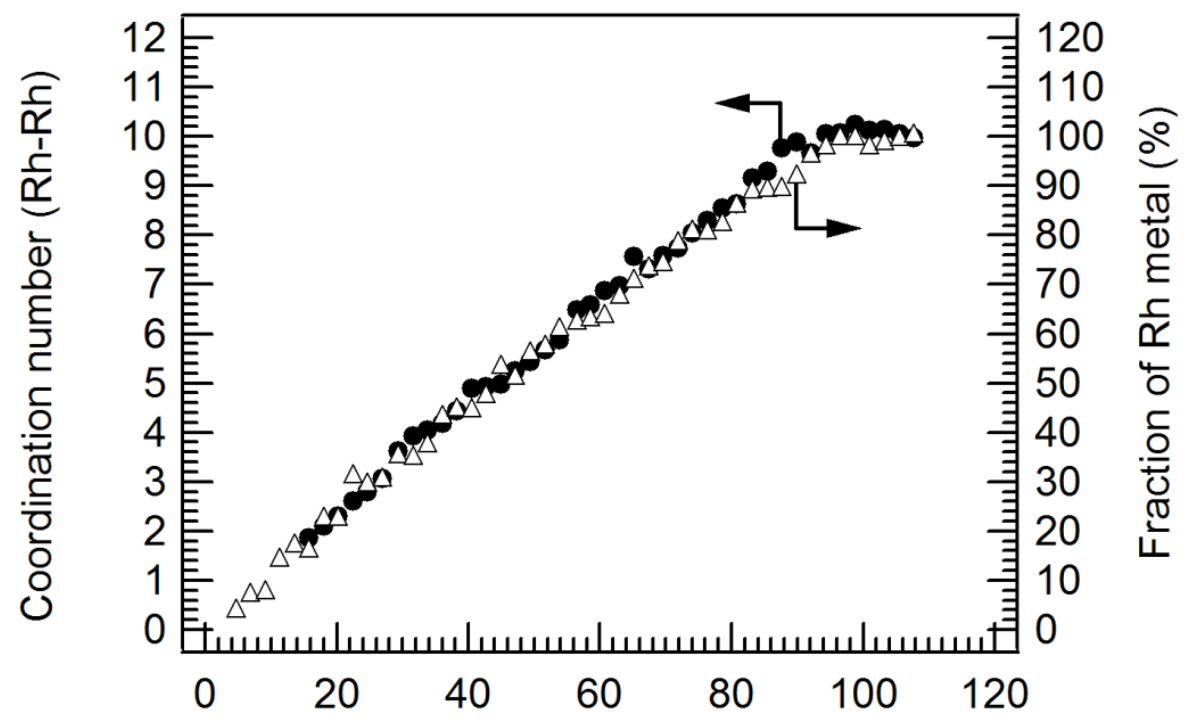

Photoirradiation time / $\mathrm{min}$

\section{Figure 12}




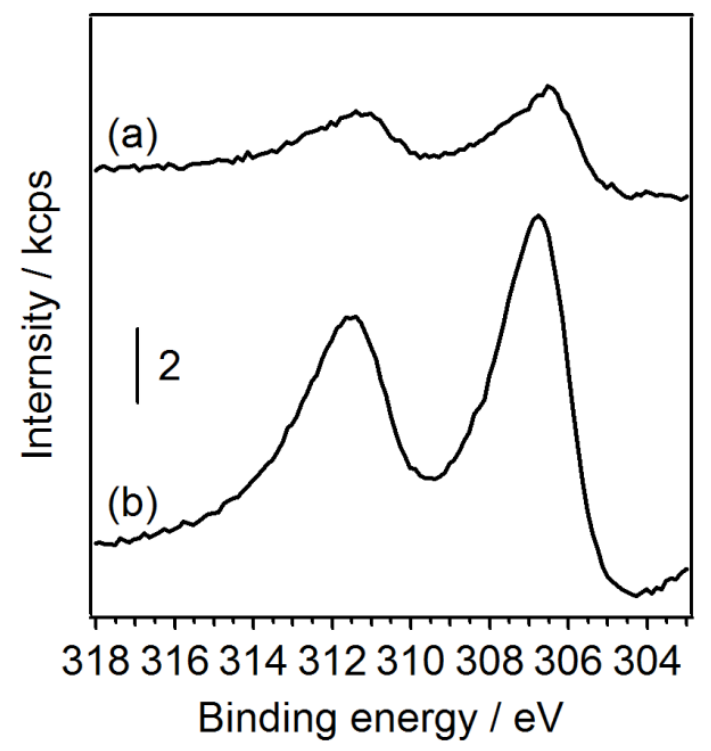

Figure 13 


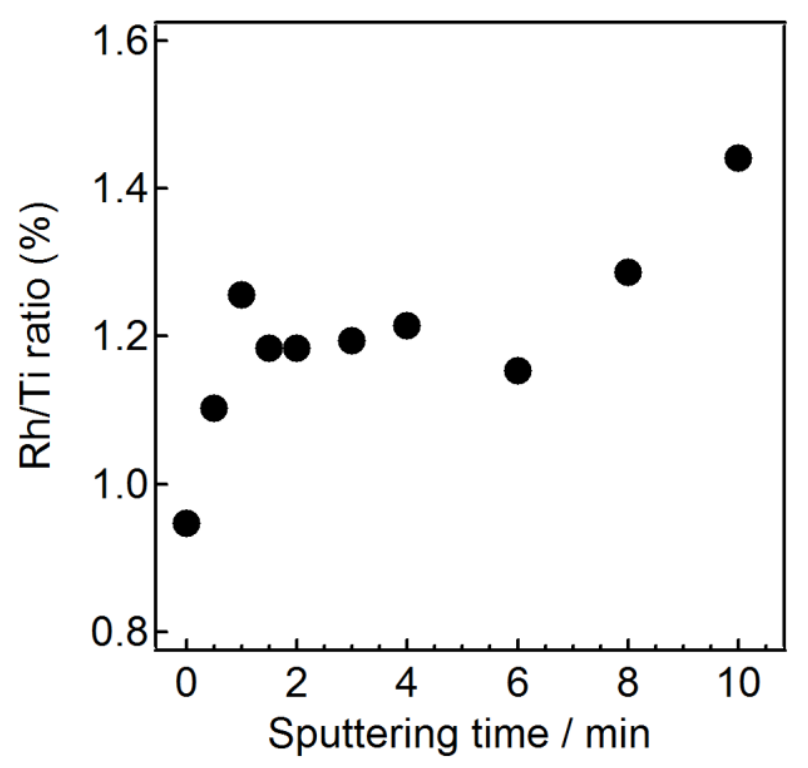

Figure 14 


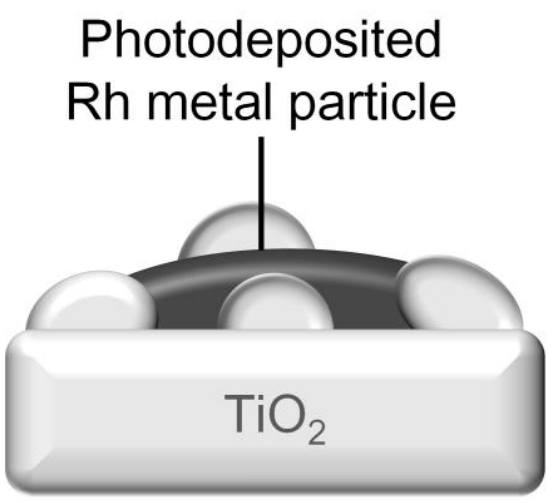

Figure 15 


\section{SCHEMES.}

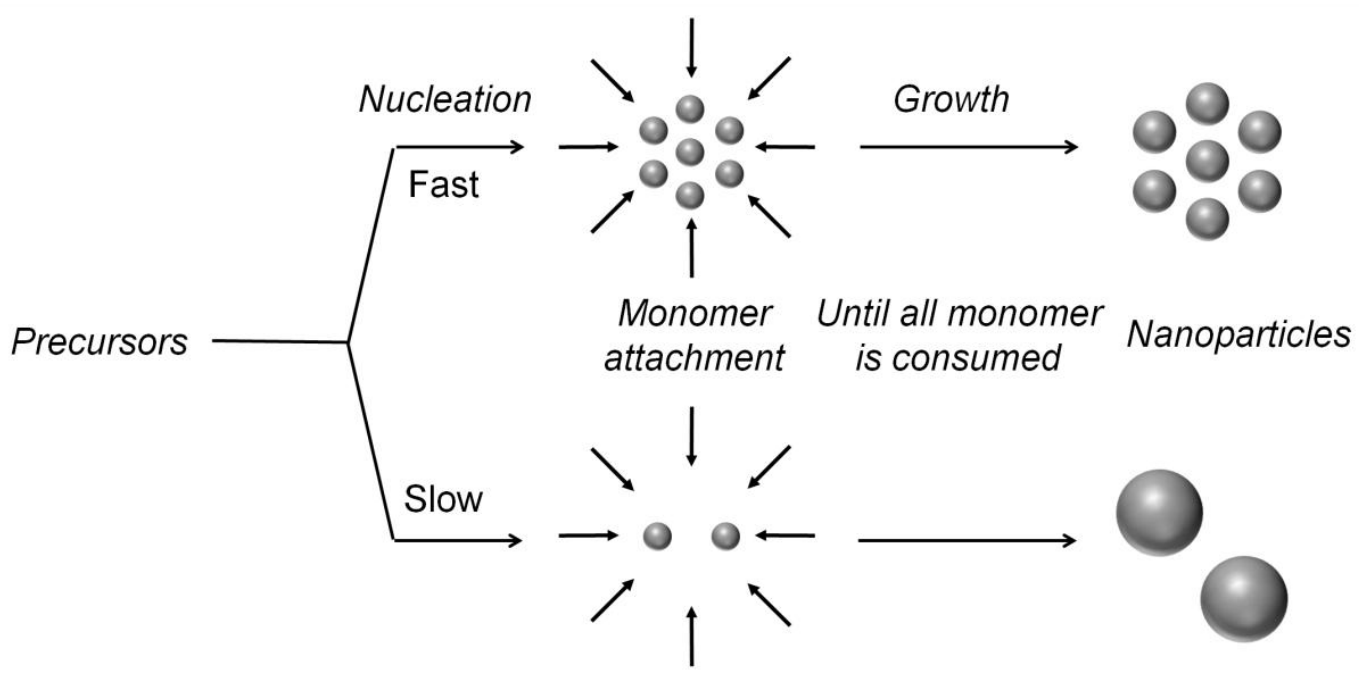

Scheme 1 

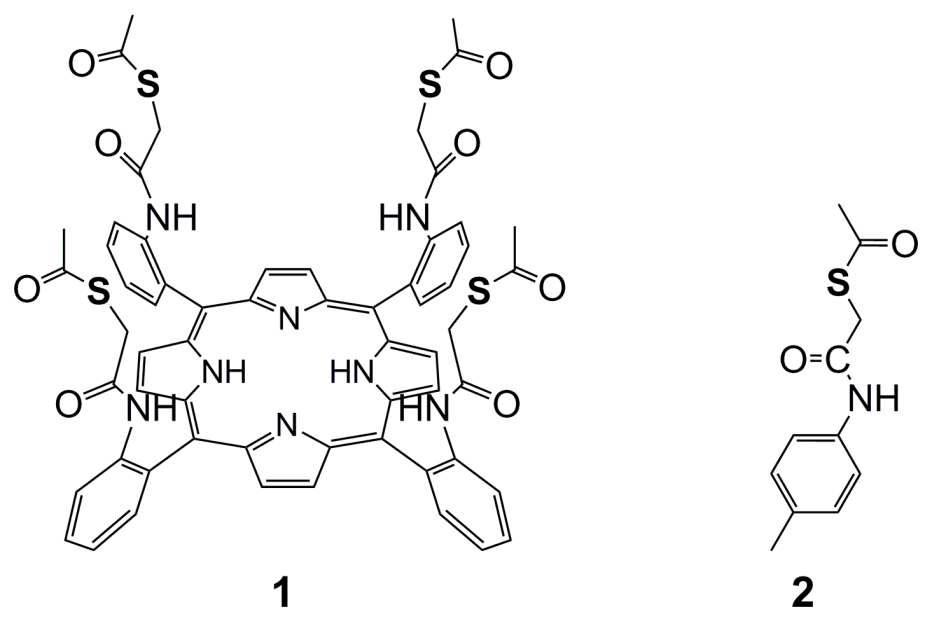

Scheme 2 


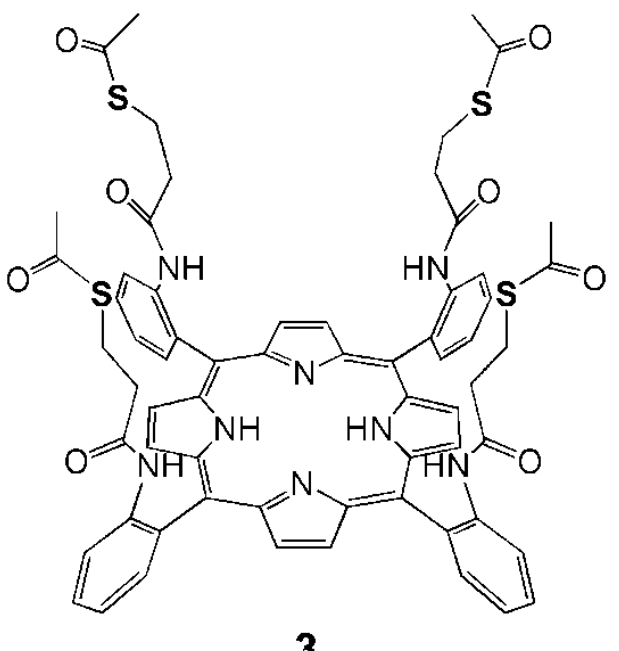

3

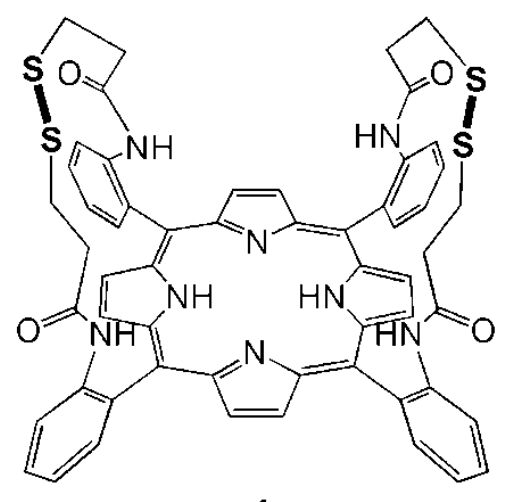

4

Scheme 3 
sิo?

†ेs

(I)

4<smiles></smiles>

5

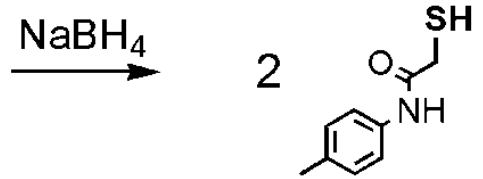

5

Scheme 4 


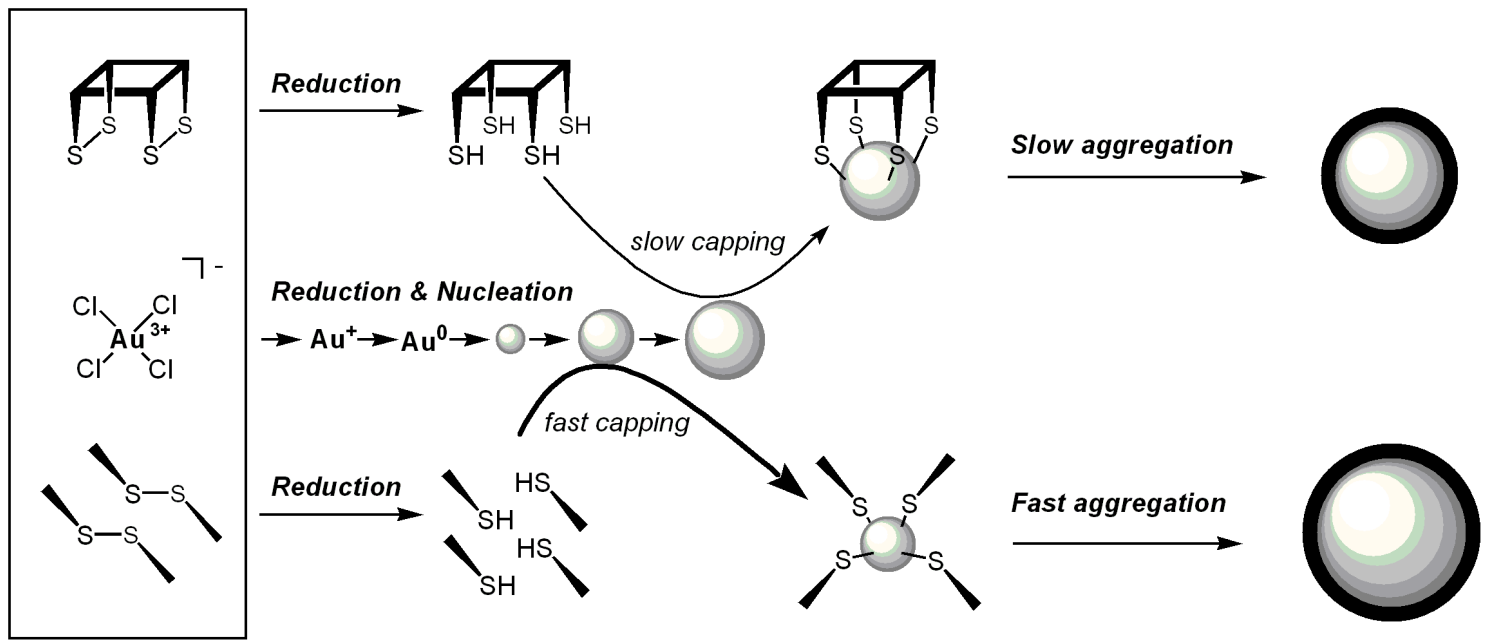

\section{Scheme 5}

